\title{
CEsifo WORKING

\section{Price Effects of the Austrian Fuel Price Fixing Act: A Synthetic Control Study}

Maike Becker, Gregor Pfeifer, Karsten Schweikert 


\section{Impressum:}

CESifo Working Papers

ISSN 2364-1428 (electronic version)

Publisher and distributor: Munich Society for the Promotion of Economic Research - CESifo

$\mathrm{GmbH}$

The international platform of Ludwigs-Maximilians University's Center for Economic Studies and the ifo Institute

Poschingerstr. 5, 81679 Munich, Germany

Telephone +49 (0)89 2180-2740, Telefax+49 (0)89 2180-17845, email office@cesifo.de

Editor: Clemens Fuest

https://www.cesifo.org/en/wp

An electronic version of the paper may be downloaded

- from the SSRN website: www.SSRN.com

- from the RePEc website: $\quad$ www.RePEc.org

- from the CESifo website: https://www.cesifo.org/en/wp 


\title{
Price Effects of the Austrian Fuel Price Fixing Act: A Synthetic Control Study
}

\begin{abstract}
Fuel prices are commonly perceived to be excessively high, which regularly triggers political discussions about fuel price regulations. Consumers demand stricter fuel price regulations to provide transparency about the current price level and to protect them from sudden price fluctuations. Such regulations are already in place in several countries, but whether they indeed help lower the overall fuel price level is unclear. In this paper, we study the effect of Austria's Fuel Price Fixing Act on gasoline and diesel price levels. Using the synthetic control method, we construct a counterfactual and estimate Austria's price trends in absence of the intervention. Our empirical results suggest, that immediately after the Fuel Price Fixing Act came into effect, gasoline prices are $23.4 \%$ lower than the synthetic control predicts. The effect on diesel prices appears to be less pronounced and amounts to 6.6\% lower prices. Austria's fuel price regulation seems to have been effective in terms of gasoline prices but may need further refinements to effectively tackle diesel prices as well.
\end{abstract}

JEL-Codes: C220, D430, Q410.

Keywords: causal effects, diesel, gasoline, price regulation, retail fuel prices.

Maike Becker
Chair of Innovation Management
University of Hohenheim
Schloss Hohenheim 1 C
Germany - 70593 Stuttgart
maike.becker@uni-hohenheim.de

Gregor Pfeifer

University of Sydney

School of Economics

Social Sciences Building

Australia - NSW 2006 Sydney

g.pfeifer@ucl.ac.uk
Karsten Schweikert

Core Facility Hohenheim \& Institute of

Economics, University of Hohenheim

Schloss Hohenheim $1 \mathrm{C}$

Germany - 70593 Stuttgart

karsten.schweikert@uni-hohenheim.de 


\section{Introduction}

A common public perception is that fuel prices are higher than they should be. Multinational oil companies are accused of transmitting changes from crude oil prices to retail fuel prices only partially and with substantial delay. The public discussion usually includes demands for stricter fuel price regulations to restrict the market power of retailers. As a matter of fact, some retail fuel markets are strongly regulated, and fuel price regulations are already implemented in several countries. In general, two different designs can be observed in practice. One approach is to dictate price ceilings or price floors, valid either for wholesale or retail prices. Most often, retailers are legally bound not to exceed a predetermined maximum retail fuel price. Such regulations are present, for example, in Luxembourg, Belgium and in some Canadian provinces. Another approach pursued by policy makers is intended to mitigate price fluctuations by regulating frequency and timing of price changes. For instance, in 2001, Western Australia set regulations according to which retailers must fix constant daily fuel prices one day in advance. Similarly, Austria implemented the Fuel Price Fixing Act in 2009, allowing retailers to increase daily fuel prices only once at the beginning of the day. Although these regulations are discussed as potential measures to lower fuel prices, their actual effects on retail fuel prices are largely unknown. Particularly, it is unclear whether these regulations affect gasoline and diesel markets differently.

In this paper, we study price effects of the Austrian fuel price intervention using the synthetic control method (SCM) framework introduced by Abadie and Gardeazabal (2003) and Abadie et al. (2010). In order to estimate a causal effect of the intervention, we construct a counterfactual from a control group based on pre-intervention characteristics. Because this framework allows us to estimate dynamic treatment effects, we are able to estimate both short-run and long-run effects of the Fuel Price Fixing Act. While the short-run effects are evaluated at the end of 2009, we need to be more cautious when estimating the long-run effects because the initial Fuel Price Fixing Act was revised in 2011 and again in 2012. Furthermore, the Law on Transparency of Fuel Prices was enacted in August 2011, requiring retailers to forward any price changes to a regulatory agency that publishes retail fuel prices online. Consequently, estimating long-run effects of this policy at one point in time after 2011 could be picking up additional effects of its revisions and the Law on Transparency of Fuel Prices. However, using our comparison between Austria and the synthetic control group, we can show whether the enactment of those policies coincides with a narrowing or widening of the 
gap between their fuel price levels. ${ }^{1}$ We estimate individual models for gasoline and diesel prices to capture potentially heterogeneous price effects.

Although fuel price regulations differ in their design, the underlying intention is the same: improving transparency for consumers and increasing competition between retailers. At first sight, it may appear surprising to target fuel prices because there are very few industries where prices are similarly transparent. However, fuel prices exhibit an overly volatile behavior still leaving consumers with much uncertainty about the current price level. As a result, consumers trying to fuel their vehicles at the lowest possible price face high search costs. Increasing transparency therefore primarily aims at reducing these search costs by decreasing volatility. One strand of literature is concerned with the effects of fuel price regulations on volatility (Suvankulov et al., 2012) and on price transmission dynamics (Fasoula and Schweikert, 2020). Effects on the price level are studied empirically, inter alia, in Wang (2009), Suvankulov et al. (2012) and Dewenter et al. (2017). However, forcing retailers to follow a pricing strategy with infrequent price changes may also facilitate tacit collusion and thereby increase the price level. Thus, another strand of literature is devoted to the evaluation of fuel price regulations on the tendency to collude (see, e.g., Andreoli-Versbach and Franck, 2015; Genakos et al., 2018).

Due to the fact that the Austrian fuel market is strongly regulated compared with other member states of the European Union (IEA, 2014), investigating the effects of Austria's fuel price intervention is a particularly interesting research object. However, studies focusing on the case of Austria are rare. Except for Dewenter et al. (2017), existing studies use theoretical and experimental designs to identify price effects (see, e.g., Berninghaus et al., 2012; Haucap and Müller, 2012; Obradovits, 2014). Following the arguments of Pennerstorfer et al. (2020), increased transparency should intensify competition and thereby directly lower the overall price level. Berninghaus et al. (2012), on the contrary, argue that Austria's fuel price regulations facilitate tacit collusion and lead to higher fuel prices. To examine empirically whether the Austrian fuel price regulations indeed lowered prices is the main objective of this study.

Standard difference-in-differences (DiD) methods are typically applied to estimate causal effects of an intervention while controlling potentially unobserved factors. Specifically, DiD assumes that the controls' outcome follows a trajectory with a trend parallel

\footnotetext{
${ }^{1}$ Alternatively, we could try to model the staggered nature of those policies explicitly, but this is not feasible considering the short period between them and the unavailability of most predictor variables at a higher frequency.
} 
to that of the treated unit before the intervention. Confounders may vary across groups but do not vary over time and vice versa. In our setting, the intervention applies to a country as a whole. Identifying a suitable control group, (i.e., countries demonstrably similar to the treated country) poses a major challenge. In order to evaluate price effects of the Austrian fuel price intervention, it seems reasonable to choose other European countries with similar characteristics as potential control units. Because most countries do not fulfill the parallel trends assumptions, we deviate from the standard DiD approach and apply the SCM. It relaxes the parallel trends assumption and provides a data-driven approach to estimate a synthetic control group. More precisely, it constructs a convex weighted average of potential control countries based on pre-treatment values of variables that are predictors for fuel prices. The major advantage of SCM lies in its ability to control for unobserved confounders affecting the trajectory of the outcome variable. Furthermore, it allows the effect of the fuel price intervention to vary over time. Since its conception, the SCM has been applied in numerous studies across a variety of disciplines evaluating, for example, the effects of health policy (Bauhoff, 2014; Kreif et al., 2016), immigration policy (Bohn et al., 2014), crime (Pinotti, 2015), and, more recently, energy policy (Rickman et al., 2017; Rickman and Wang, 2020; Jardón et al., 2020).

This paper contributes to the literature in three ways. First, we extend an asyet scant and contradictory body of literature on the effects of fuel price regulations. Second, we focus on estimating the effects on the fuel price levels, which are at the heart of the public discussion, instead of focusing on price volatility or price adjustment dynamics. Third, we apply the SCM to address the fact that no natural control group exists to identify the price effects of Austria's fuel price intervention. Instead, we construct a synthetic control to identify a causal effect of the intervention.

To preview our main empirical findings, we report heterogeneous price effects for gasoline and diesel. While our results show that gasoline net prices decrease by $23.4 \%$ immediately after the implementation of the Fuel Price Fixing Act in 2009, the effect on diesel net prices appears to be less pronounced and amounts to a $6.6 \%$ decrease by the end of 2009. The heterogeneous price effects might be explained by the larger share of commercial users in the diesel market and their unresponsiveness to reduced search costs. In terms of long-run effects, we find that gasoline and diesel prices are reduced by $7.5 \%$ and $5.4 \%$, respectively. We can partially confirm the empirical findings of Dewenter et al. (2017) that Austria's fuel price regulation does not lead to higher retail fuel price levels, and thereby contradict existing theoretical and lab-experimental 
studies (Berninghaus et al., 2012; Haucap and Müller, 2012; Obradovits, 2014; Angerer, 2019).

The remainder of this paper is structured as follows: Section 2 is devoted to the formation of retail fuel prices to motivate the choice of explanatory variables used in the empirical analysis. It highlights the major determinants of fuel prices and describes Austria's fuel price intervention in detail. Moreover, a brief literature review on the effects of fuel price regulations is provided. In Section 3, the SCM is described in detail and the empirical application thereof is presented in Section 4. Lastly, Section 5 concludes and offers some policy implications.

\section{Theoretical Background}

\subsection{Determinants of fuel prices}

Retail fuel prices are almost completely determined by the costs for crude oil and by taxes. While, in Austria, a value added tax of $20.0 \%$ is equally imposed on both fuel types, the fixed mineral oil tax is generally lower for diesel than for gasoline (EuroSuper). ${ }^{2}$ Together these taxes account for more than $50.0 \%$ of the final retail price. The lower mineral oil tax for diesel is one reason why the share of diesel-powered cars (55.8\%) is higher than the share of gasoline-powered cars (43.0\%) in Austria.

Gasoline is almost exclusively consumed for the use of passenger cars and motor cycles. On the contrary, diesel is predominantly used in goods transport, machinery, and the agricultural sectors. While gasoline consumption amounted to 1.7 million tons in 2018, diesel consumption amounted to 7.0 million tons. Only $57.0 \%$ thereof was sold at publicly available filling stations, and the remaining $43.0 \%$ was stored in corporate deposits of transport or building companies (Fachverband Mineralölindustrie, 2019). The costs for crude oil account for $36.0 \%$ (41.0\%) of the final retail gasoline (diesel) price. Like all European countries, Austria is not able to satisfy domestic demand for crude oil by itself and therefore heavily depends on imports. In 2018, Austria imported 8.3 million tons of crude oil from nearby oil-producing countries. Crude oil is delivered via the Adria-Vienna Pipeline to Austria's only refinery in Schwechat. Both the pipeline and the refinery are owned by the Austrian oil and gas company OMV. Another 664 thousand tons of crude oil are produced domestically by OMV and RAG

\footnotetext{
${ }^{2}$ In 2018, the mineral oil tax levied on diesel amounted to 39.7 Euro cents per liter, whereas gasoline was taxed with 48.3 Euro cents per liter.
} 
Austria. After being refined and blended, fuels are stored in depots. These depots are operated by a small number of integrated multinational oil and gas companies: OMV (Austria), MOL (Hungary), Eni (Italy), and Shell (the Netherlands, UK). Finally, fuels are distributed to local filling stations. Costs for transportation, maintenance, and personnel then account for the remaining 8.0\% of gasoline and diesel retail prices (Fachverband Mineralölindustrie, 2019).

Apparently, the Austrian fuel market is characterized by an oligopolistic market structure. In 2018, 1357 of 2699 filling stations were operated by six major companies: Avanti (139), BP (266), Eni (323), JET (154), OMV (213), and Shell (262). How-

ever, the number of filling stations operated by these companies appears to decrease over time, which can be interpreted as a step towards more competition (Fachverband Mineralölindustrie, 2019). Still, fuel markets are often viewed as a paramount example for tacit collusion (Borenstein and Shepard, 1996; Eckert and West, 2004; Wang, 2009; Perdiguero, 2010). Frequently, extensive vertical relations and mutual dependencies are present, enabling price coordination between retailers (OECD, 2013).

\subsection{Austrian fuel price intervention}

In July 2009, the Federal Ministry of Economy, Family and Youth enacted a law that regulates the pricing strategy of Austrian filling stations. The Fuel Price Fixing Act ('Spritpreisverordnung') stipulated that retailers were allowed to increase their prices only in the morning, while price cuts were allowed at any time (BMWFJ, 2009). More precisely, filling stations, which are open 24 hours a day, were legally bound to determine and set their maximum price at midnight. Filling stations with limited opening hours had to do so as soon as they opened. In case of self-service terminals at unmanned filling stations, a price increase was only possible until 8:30 a.m. The initial temporary regulation discontinued at the end of 2010. In January 2011, the regulation was renewed in slightly revised form and now permits all operators to increase their prices once a day at 12:00 p.m. (BMWFJ, 2010). In August 2011, the enactment of the Law on Transparency of Fuel Prices ('Preistransparenzverordnung Treibstoffpreise 2011') additionally required filling stations to forward any price changes within half an hour to the Austrian Energy Regulator, E-Control. Prices are posted online which enables consumers to compare stations and to find the lowest price (BMWFJ, 2011). In 2012, the Fuel Price Fixing Act was further refined and obliged operators to freeze prices on the Easter weekends and the first two weekends of the summer holidays (BMWFJ, 
2012). Since 2012, the Fuel Price Fixing Act and the Law on Transparency of Fuel Prices have been renewed jointly without any major changes. ${ }^{3}$

Clearly, these regulations help decrease price volatility and improve transparency. However, it is not clear to which extent they are suitable means to reduce the price level. Because crude oil prices and taxes are the same across Austria, price dispersion must be attributed to individual sales costs and local market characteristics. Still, fuel prices differ significantly even between filling stations with similar market power and close geographic proximity, although the product sold is highly homogeneous in its physical features. Consumers may perceive differences between filling stations through advertising and brand image. Additionally, effective differentiation is based on location advantages and services offered, such as the existence of convenience stores or the number of pumps. According to Pennerstorfer et al. (2020), these characteristics can easily be controlled for in their empirical study and do not completely explain the dispersion in Austrian retail fuel prices. In theory, price dispersion in homogeneous goods markets can partly be ascribed to imperfect information (Stigler, 1961). A higher share of informed consumers is expected to lead to more competition among filling stations and thus to lower prices. Pennerstorfer et al. (2020) proxy the share of informed consumers by that of long-distance commuters who are able to scan prices at many different stations. Therefore, they are better informed and face lower search costs for finding the the best price than non-commuters. Indeed, Pennerstorfer et al. (2020) find empirical evidence that the share of informed consumers has a negative effect on fuel prices.

The search cost hypothesis in the context of fuel markets is discussed by Johnson (2002), Yang and Ye (2008), Lewis (2011), and Byrne and de Roos (2020). Lewis (2011) argues that consumers search more intensively when the wholesale prices are increasing, e.g., through higher costs for crude oil. Conversely, consumers search less intensively when wholesale prices are decreasing. Filling stations that do not lower their retail prices at the same speed may temporarily operate at higher margins. Lowering the search costs in a market by increasing transparency should therefore lower the overall price level.

On the other hand, it could be easier for retailers to maintain a tacit collusion equilibrium under the Fuel Price Fixing Act because they would be faced with less frequent price changes, having to coordinate only a daily maximum price and the subsequent

\footnotetext{
${ }^{3}$ Retailers were required to freeze prices over every prolonged weekend in 2013 . This practice was discontinued in December 2013 (BMWFJ, 2013).
} 
(potential) price decreases. Byrne and De Roos (2019) study the tacit communication of retailers in the Australian fuel market and find that the clear price leadership of the largest retailer can lead to a margin-enhancing pricing structure. Moreover, it can be expected that retailers adjust to the new requirements and charge higher initial prices (Obradovits, 2014). Consequently, it is unclear a priori how the Austrian fuel price regulation affects fuel price levels.

To investigate the hypothesis that companies would set higher prices under conditions defined by the Austrian-type fuel price regulation, Berninghaus et al. (2012) evaluate a game theoretical lab experiment. Their results suggest that prices in regulated markets are higher but less volatile compared with non-regulated markets. In another lab experiment, Haucap and Müller (2012) compare the effects of three different fuel price regulations (Luxembourg, Western Australia, Austria). They find that none of them lowers retail prices. Obradovits (2014) conducts a theoretical analysis in a two-period duopoly model with consumer search and finds that the Austrian-type fuel price regulation has detrimental effects on consumer welfare. Finally, Angerer (2019) revisits the lab-experimental setting of Haucap and Müller (2012) and predicts that the Austrian-type fuel price regulation produces more intra-day volatility and less efficient prices.

\subsection{Empirical evidence on the effects of fuel price regulations}

An extensive body of literature is concerned with analyzing fuel markets in terms of competition and asymmetric price transmission (for a detailed review see, e.g., Eckert, 2013; Perdiguero-García, 2013). However, only a few empirical studies do so by considering fuel price regulations. Suvankulov et al. (2012) investigate the effect of the Petroleum Product Pricing Act introduced in the Canadian provinces Nova Scotia and New Brunswick in 2006. While maximum and minimum prices are set in Nova Scotia, only a maximum price is set in New Brunswick. The authors find that the gasoline prices in Nova Scotia did not converge to the national mean, but prices in New Brunswick converged and had lower volatility, indicating that the latter regulation served its purpose. Price ceilings on retail gasoline prices in Eastern Canadian provinces are also assessed by Sen et al. (2011). The authors find that price ceilings lead to higher prices and explain this finding by tacit collusion, which is made easier having state-mandated price ceilings as focal points. Carranza et al. (2015) provide an extensive analysis of the effects of introducing price floor regulations in the province 
of Québec and find that price floor regulations result in lower prices. Price ceilings were also prevalent in Spain until 1998 (Contín-Pilart et al., 2009) and are nowadays still implemented in Luxembourg and Belgium (IEA, 2009, 2011). However, empirical research for these countries is rare.

Wang (2009) studies the dynamic pricing strategies of retailers before and after the enactment of the Western Australian regulation, which constrains each filling station in the Perth metropolitan area to set the next day's retail price by 2:00 p.m. He finds that the intervention initially impedes price coordination among retailers, resulting in lower prices. Immediately after the intervention is implemented, the average price in Perth decreases and remains below the average prices in the control units. However, this effect is present only temporarily. After four months, prices converge, indicating that retailers managed to engage in price coordination again. In contrast, Dewenter et al. (2017) use the DiD method and find that Western Australia's fuel price regulation does not have a significant effect on price levels. As opposed to Wang (2009), they argue that the regulation does not prohibit collusive behavior so that price levels remain unaffected.

Dewenter et al. (2017) also evaluate the effects of Austria's fuel price intervention, which allows retailers to be more flexible in their price setting behavior. The case of Austria differs from the Western Australian regulation in the important aspect that it is applied nationally instead of being restricted to selected provinces or regions. Finding a suitable control group is more difficult in this case because countries are clearly more heterogeneous than regions within the same country. Initially, Dewenter et al. (2017) consider all EU25 countries as potential control countries. ${ }^{4}$ Because DiD requires that price trends of control countries are parallel to the price trend of Austria before the intervention, they restrict their sample to Belgium, Denmark, France, Germany, Ireland, Sweden, and the United Kingdom. DiD regressions are then estimated separately for each comparison country. The results suggest that prices of both fuel types decrease by 2 to 4 Euro cents per liter after the intervention. Interestingly, the authors set the point of intervention in 2011, the year of the first revision. This means that their preintervention period includes two years in which the Austrian fuel market was already regulated by the Fuel Price Fixing Act, a choice that we hypothesize could change results and remains to be tested empirically. In contrast, our study focuses on the

\footnotetext{
${ }^{4}$ EU25 refers to the 25 member states of the European Union before the second Eastern Enlargement in 2007: Austria, Belgium, Cyprus, Czech Republic, Denmark, Estonia, Finland, France, Germany, Greece, Hungary, Ireland, Italy, Lithuania, Luxembourg, Latvia, Malta, Poland, Portugal, Spain, Sweden, Slovenia, Slovakia, the Netherlands, and United Kingdom.
} 
initial Fuel Price Fixing Act in 2009, providing new empirical results for the period from 2009 until 2011. Moreover, we address the difficulties in finding a suitable control group using the SCM framework, which does not rely on the parallel trend assumption and allows us to study dynamic treatment effects.

There is one prior study applying the SCM in the context of fuel markets. AndreoliVersbach and Franck (2015) consider the Italian fuel market and investigate the effects of the market leader Eni's announcement to change its price setting behavior. In October 2004, Eni publicly committed to a pricing strategy that reduces the frequency of price changes while simultaneously increasing their amplitude. The authors find that fuel prices significantly increased suggesting an anti-competitive effect of Eni's pricing policy. While these results are important to understand the effects of price-commitment for collusive agreements, they do not translate straightforwardly to our setting where a national fuel price regulation is imposed uniformly for all competitors.

\section{Methodology}

The SCM is particularly useful to infer causal effects of an intervention taking place on an aggregate level and affecting only one or very few units. A potential pitfall of alternative approaches, like the controlled (comparative) interrupted time series design (CITS) or the DiD design, lies in the underlying, rather restrictive assumption of parallel trends. More precisely, for DiD to yield unbiased estimates, outcome trends of the treated and control unit must be parallel prior to the intervention. This assumption implies that any effect caused by unobservable confounders is constant over time and can thus be removed by taking time differences.

The SCM relaxes the assumption of parallel trends. The synthetic control unit is designed such that it closely approximates the outcome trajectory of the treated unit. By assigning different weights to control units based on their similarity to the treated unit in terms of pre-intervention characteristics, the SCM allows for the effects of unobservable confounders to vary over time (Abadie and Gardeazabal, 2003). Put differently, because the difference between the treated and the synthetic control unit is minimized over the pre-intervention period, discrepancies in trends are, by construction, minimized. 


\subsection{Model}

Throughout this section, we follow the notation of Abadie et al. (2010) and Abadie (2019). We consider a setting where $J+1$ countries are observed over $t=1, \ldots, T_{0}, T_{0}+$ $1, \ldots, T$ periods and only one country, $j=1$, is exposed to the intervention, henceforth referred to as the treated country. The intervention is implemented in $t=T_{0}+1 \mathrm{such}$ that $t=1 \leq t \leq T_{0}$ defines the pre-intervention window and $T_{0}+1 \leq t \leq T$ defines the post-intervention window, respectively. The remaining $j=2, \ldots, J+1$ countries are not affected by the intervention and serve as potential control countries, constituting the socalled donor pool. Furthermore, we assume that there are no anticipation and spillover effects such that the intervention neither affects the outcome prior to its implementation nor the outcome of any other donor pool country in the post-intervention period. In the case of the Austrian Fuel Price Fixing Act, both assumptions are likely to hold. Although the intervention was announced in advance, it appears unlikely that filling stations adjusted their price setting strategy or consumers changed their behavior prior to the implementation in $2009 .{ }^{5}$ In addition, it seems to be unlikely that fuel prices in other countries directly reacted to the intervention. If there were any spillover effects, they would only affect border areas and would not significantly influence national price averages. Note that both assumptions must be met in DiD designs as well.

Now let $Y_{j t}$ denote the outcome of interest for each country $j$ in period $t$ and let $Y_{j t}^{N}$ be the outcome at period $t$ in the absence of the intervention. ${ }^{6}$ For country $j=1$, which, in this paper, is the only unit exposed to the intervention, we additionally differentiate between $Y_{1 t}^{N}$ and $Y_{1 t}^{I}$, where the latter refers to the outcome under the intervention. Naturally, $Y_{1 t}^{I}$ is exclusively observed during the post-intervention window. Accordingly, the outcome of interest for each country can be expressed as:

$$
Y_{j t}=Y_{j t}^{N}+\alpha_{j t} D_{j t}
$$

\footnotetext{
${ }^{5}$ We estimated the same model specifying the treatment one year earlier to rule out potential anticipation effects. We do not find a substantial deviation of the Austrian fuel price levels from their synthetic controls before the implementation in 2009. The short-run and long-run results of the Fuel Price Fixing Act remain robust and are reported in the Online Appendix to this paper, see https://karstenschweikert.github.io/scm_fuel_supp_material_20201223.pdf.

${ }^{6}$ In order be able to apply the inference technique discussed in Subsection 3.3, the outcome of interest is required to be observable over the entire time span $t=1, \ldots, T$ for all $J+1$ countries.
} 
where

$$
D_{j t}= \begin{cases}1, & \text { if } j=1 \text { and } t>T_{0} \\ 0, & \text { otherwise, }\end{cases}
$$

such that, for $t>T_{0}$ the effect of the intervention is captured by

$$
\alpha_{1 t}=Y_{1 t}^{I}-Y_{1 t}^{N}=Y_{1 t}-Y_{1 t}^{N}
$$

Note that $\alpha_{1 t}$ is not constant over time and thus allows for gradually evolving effects. While $Y_{1 t}^{I}$ are the post-intervention outcomes observed in the data, $Y_{1 t}^{N}$ for $t>T_{0}$ needs to be estimated because it refers to the counterfactual outcome trajectory that would have evolved had the treated country not been exposed to the intervention. To do so, the SCM suggests reproducing $Y_{1 t}^{N}$ for $t>T_{0}$ by means of a weighted average, more precisely a convex combination of donor pool countries. Weights are constructed based on pre-intervention characteristics of the respective countries. These characteristics can be understood as predictors for the outcome of interest. By constraining weights to be non-negative and to sum up to one, the SCM precludes extrapolation bias. ${ }^{7}$ However, Abadie et al. (2010) point out that the synthetic control estimator can be prone to interpolation bias. The latter occurs when the treated country's characteristics are replicated using donor pool countries whose characteristics differ substantially from those of the treated country. Prediction is more difficult if data points lie close to the edge of the convex hull, bearing the risk of overfitting. In order to mitigate interpolation bias, potential control countries are required to be demonstrably similar to the treated country in terms of these characteristics. Simply put, the treated country's value of each predictor should not be extremely high or extremely low relative to the predictor values of the other countries because such extreme values cannot be closely approximated by the synthetic control. Fortunately, the advantage of the SCM over other causal inference methods is that the goodness of fit can be evaluated explicitly. Although Abadie et al. (2010) recommend including lagged outcome values together with other relevant predictors (covariates), Kaul et al. (2015) warn against using the entire pretreatment path of the outcome variable together with such other predictors. In this case, important predictors (covariates) could be ignored, leading the estimator to be

\footnotetext{
${ }^{7}$ Extrapolation may produce nonsensical estimates beyond the support of the data. However, allowing for extrapolation appears to be reasonable in settings in which the treated unit is extreme, meaning that its outcome is systematically smaller or larger relative to the remaining units. Some authors relax the assumption of the treated unit being inside the convex hull of the other units and allow negative weights (see, e.g., Hsiao et al., 2012; Doudchenko and Imbens, 2016).
} 
biased.

Assume that for each country $j$ there are pre-intervention observations available for $K$ predictors. For each country $j$, the predictors are captured by a $(K \times 1)$ vector so that we have $\mathbf{X}_{1}, \ldots, \mathbf{X}_{J+1}$. More precisely, $\mathbf{X}_{j}$ has $K$ entries consisting of pre-intervention averages for each predictor. The $(K \times J)$ matrix $\mathbf{X}_{\mathbf{0}}$ then subsumes the predictors for $J$ untreated countries. Note that, while the outcome of interest is required to be observable over the entire time span $t=1, \ldots, T$ for all $J+1$ countries, data on the predictors must be available for at least one pre-intervention period.

\subsection{Estimation}

As mentioned above, the synthetic control is given as a weighted average of donor pool countries. Consider a $J \times 1$ vector of weights $\mathbf{W}=\left(w_{2}, \ldots, w_{J+1}\right)^{\prime}$, where $w_{j} \geq 0$ and $\sum_{j=2}^{J+1} w_{j}=1$. For $t>T_{0}$ the counterfactual $Y_{1 t}^{N}$ is estimated as

$$
\hat{Y}_{1 t}^{N}=\sum_{j=2}^{J+1} w_{j} Y_{j t} .
$$

Accordingly, the estimator of the causal effect $\alpha_{1 t}$ is given by

$$
\hat{\alpha}_{1 t}^{N}=Y_{1 t}-\hat{Y}_{1 t}^{N}
$$

The SCM is based on the idea that there exists a set of weights such that a weighted average of the control countries using those weights is able to closely approximate the pre-intervention predictor values of the treated country. Put differently, donor pool countries should be combined such that the discrepancy in predictor values is minimized. Following Abadie and Gardeazabal (2003) and Abadie et al. (2010), W is chosen such that it minimizes the the Euclidean distance

$$
\left\|\mathbf{X}_{1}-\mathbf{X}_{\mathbf{0}}\right\|=\sqrt{\left(\mathbf{X}_{1}-\mathbf{X}_{\mathbf{0}} \mathbf{W}\right)^{\prime} \mathbf{V}\left(\mathbf{X}_{1}-\mathbf{X}_{\mathbf{0}} \mathbf{W}\right)}
$$

where $\mathbf{V}$ is a $(K \times K)$ positive diagonal matrix that contains positive weights $v_{1}, \ldots, v_{K}$ for each predictor. Note that only pre-intervention predictor values are used for estimation. They are not used to predict the post-intervention gap but serve as a constraint for estimating W. Therefore, predictor weights do not reflect how important that variable is for predicting the outcome but how important it is in estimating $\mathbf{W}$. 
The estimation procedure then follows an iterative process. ${ }^{8}$

1. Select an arbitrary initial positive-definite diagonal matrix $\mathbf{V}_{\mathbf{i n}}$, e.g., the identity matrix.

2. Given this initial $\mathbf{V}_{\mathbf{i n}}$, obtain a first synthetic control $\mathbf{W}^{*}\left(\mathbf{V}_{\text {in }}\right)$, such that

$$
\begin{aligned}
\mathbf{W}^{*}\left(\mathbf{V}_{\mathbf{i n}}\right)=\underset{\mathbf{W}}{\arg \min } & \sqrt{\left(\mathbf{X}_{\mathbf{1}}-\mathbf{X}_{\mathbf{0}} \mathbf{W}\right)^{\prime} \mathbf{V}_{\mathbf{i n}}\left(\mathbf{X}_{\mathbf{1}}-\mathbf{X}_{\mathbf{0}} \mathbf{W}\right)} \\
\text { s.t. } & \sum_{j=2}^{J+1} w_{j}=1 \text { and } w_{j} \geq 0, j=2, \ldots, J+1 .
\end{aligned}
$$

3. Given $\mathbf{W}^{*}\left(\mathbf{V}_{\text {in }}\right)$, find a new $\mathbf{V}^{*}$ that minimizes the mean squared prediction error of the synthetic control estimator:

$$
\begin{aligned}
\mathbf{V}^{*}=\underset{\mathbf{V}_{\text {in }}}{\arg \min } & \sum_{t \in \tau_{0}}\left(Y_{1 t}-w_{2}^{*}\left(\mathbf{V}_{\mathbf{i n}}\right) Y_{2 t}-\ldots-w_{J+1}^{*}\left(\mathbf{V}_{\mathbf{i n}}\right) Y_{J+1 t}\right)^{2} \\
\text { s.t. } & \sum_{k=1}^{K} v_{k}=1 \text { and } v_{k} \geq 0, k=1, \ldots, K,
\end{aligned}
$$

for a set $\tau_{0} \subseteq\left\{1, \ldots, T_{0}\right\}$.

4. Use $\mathbf{V}^{*}$ and minimize the Euclidean distance with respect to $\mathbf{W}^{*}$ in order to obtain a second synthetic control $\mathbf{W}^{* *}\left(\mathbf{V}^{*}\right)$, such that

$$
\mathbf{W}^{* *}\left(\mathbf{V}^{*}\right)=\underset{\mathbf{W}^{*}}{\arg \min } \sqrt{\left(\mathbf{X}_{\mathbf{1}}-\mathbf{X}_{\mathbf{0}} \mathbf{W}^{*}\right)^{\prime} \mathbf{V}^{*}\left(\mathbf{X}_{\mathbf{1}}-\mathbf{X}_{\mathbf{0}} \mathbf{W}^{*}\right)}
$$

5. Keep iterating until the mean squared prediction error of the synthetic control estimator is ultimately minimized, then obtain the final and optimal $\mathbf{W}^{\mathbf{o p t}}\left(\mathbf{V}^{\mathbf{o p t}}\right)$.

\subsection{Inference}

Comparative case studies are characterized by small samples and lack randomization. Consequently, standard large sample inferential techniques cannot be applied, and re-

\footnotetext{
${ }^{8}$ Alternatively, Abadie et al. (2015) and Klößner et al. (2018) suggest a cross-validation approach where the pre-intervention period is divided into a training and a validation period such that $\mathbf{V}$ can be chosen based on out-of-sample measures. This technique is particularly useful when the preintervention window is relatively large. Because the data used to evaluate the effect of the Austrian fuel price intervention spans a relatively short pre-intervention period, the cross-validation approach is not applied in this paper.
} 
searchers cannot rely on consistency or other asymptotic properties of the estimators. In order to provide credibility of the estimated effect, Abadie and Gardeazabal (2003) and Abadie et al. (2010) propose a testing procedure similar to the well-known permutation tests. To conduct placebo tests, the SCM is applied to each control unit. More precisely, every control unit iteratively becomes the treated unit, the respective counterfactual is constructed, and the intervention effect is analyzed for each iteration, thereby providing a distribution of placebo effects. Because control units are defined as not being exposed to the intervention, their synthetic counterparts are assumed to provide a rather bad fit. The respective placebo effects are expected to be less pronounced or ideally non-existent. Abadie et al. (2010) then suggest constructing the ratio of post-intervention root mean squared prediction error (RMSPE) relative to the pre-intervention RMSPE for each synthetic control estimator. If the estimated effect on the outcome of the treated country is large relative to the distribution of placebo effects, this indicates that changes in the outcome can most likely be attributed to the intervention (Abadie et al., 2015). However, this method fails to quantify the inherent uncertainty of estimates. It reveals only whether the effect predicted for the treated unit is abnormal compared with the placebo effects and should not be interpreted as a statistical test. Because no formal inference theory has been developed for SCM estimators yet, we follow the existing literature and use the outlined placebo test for inference (Li, 2019).

\section{Empirical analysis}

\subsection{Model selection and data}

In the following section, we discuss our choice of outcome variables, the length of the pre-intervention period, the selection of predictors, and the donor pool. Detailed information on data sources are provided in Table 5 in the Appendix.

\section{Outcome of interest:}

Preliminary considerations should take into account the expected size of the effect relative to the volatility in the outcome variables (Abadie, 2019). Because high-frequency fuel prices are too volatile and most predictor variables are not available at a high frequency, we study yearly gasoline ('gsprc') and diesel prices ('dslprc'). Prices in Euro cents per liter are obtained from the Directorate General for Economic and Financial Affairs (DG ECFIN) and exclude taxes and duty so that prices are comparable across 
countries. Using net prices, moreover, ensures that our estimated policy effects are not influenced by the tax structure that might be subject to other policy changes.

\section{Length of pre-intervention period:}

Because inference is based on placebo tests applying the SCM to each donor pool country, the pre-intervention window is constrained by the availability of fuel prices for both Austria and the donor pool countries. As a consequence, the pre-intervention period is limited to the years 2000 until 2008. Not all predictor variables are available over the full pre-intervention period so that we average those variables over the available time periods (see Table 5 for details on data availability). To ensure a good fit of the synthetic control, it is important to let the pre-intervention window span several periods. Abadie et al. (2010) show that the bias of the synthetic control estimator decreases with the number of pre-intervention periods. We consider an alternative setting with a larger donor pool, which reduces the pre-intervention period to the years 2005 to 2008 (results are reported in Subsection 4.2.3 and the Online Appendix to this paper).

\section{Predictor variables:}

Predictor variables are chosen such that they proxy pre-tax fuel price determinants, as highlighted in Section 2, namely costs for crude oil, overall consumption, and market structure. Because these variables are averaged over the pre-intervention period, data only need to be available for at least one pre-intervention year. Costs for crude oil are reflected by data on crude oil import prices ('crd'), quoted in US dollars per barrel. Because we estimate the effect of Austria's fuel price intervention both on gasoline and diesel price levels, the predictors included in each model differ slightly. Per capita motor gasoline consumption in road ('mgcpc') reflects the demand for gasoline used in vehicles on public roads. Per capita diesel oil consumption in road ('dcpc') was obtained and constructed accordingly. However, diesel is predominantly used by vehicles excluded from this definition, namely those used in the agriculture, transport, and building sectors, respectively. As a result, this variable might understate the actual diesel consumption. In an attempt to mitigate bias, the share of goods road motor vehicles in total road motor vehicles (' $\mathrm{gdsvhcl}$ ') is included in the diesel model. Goods road motor vehicles are those exclusively or primarily designed to carry goods.

The following variables are used in both models and aim to match Austria's road transport infrastructure, demographic structure, and economic conditions. The variable passenger cars per one thousand inhabitants ('psngrcrs') is included in the model because an increasing number of passenger cars is associated with a higher overall consumption and and is therefore positively correlated with fuel prices (Bello and Contín- 
Pilart, 2012). Furthermore, the share of motorways in total road network ('mtrwys'), where filling stations on average charge higher prices, was chosen as another predictor variable. Presumably, mtrwys is also positively correlated with international traffic and thus with higher fuel demand.

Unfortunately, data on the market structure, e.g., on the share of large companies like Eni or Shell could not be obtained for every country. ${ }^{9}$ However, Alm et al. (2009) argue that urbanization ('urb') may proxy competition because urban areas are likely to exhibit more competition than rural areas. Following Newman and Kenworthy (1989), we assume that the average trip length in densely populated cities is often shorte, and viable alternative transportation modes are more easily available than in rural areas, for example. Similarly, Karathodorou et al. (2010) find that urbanization affects fuel consumption through lower car ownership. Moreover, GDP per capita ('gdppc') serves as an indicator of average living standard in each country. To eliminate differences in price level between countries, $g d p p c$ is denoted in US dollars using the benchmark year 2000 (International dollar). Additionally, we include GDP growth rate ('gdpgrwth') in the diesel model to capture growth in economic activity. If we would only include 'gdppc', we might miss the dynamic part of the effect (Gardeazabal and Vega-Bayo, 2017). Increased economic activity naturally affects the number of goods produced and delivered; and with an increase in goods transport, fuel consumption rises accordingly. Because trucks in transport and building sector are predominantly diesel-powered, this predictor appears to be particularly interesting when evaluating effects on diesel prices and is therefore included in the diesel model only. Furthermore, it appears to be reasonable to assume that density of road ('rddnsty'), quoted in kilometers per 100 square kilometers, contributes to a more competitive market structure: if the road network is denser, there are usually more filling stations and thus more competition, potentially leading to lower prices. On the other hand, a denser road network may also be associated with a higher share of motorways, potentially explaining the positive correlation with both fuel prices. ${ }^{10}$ Finally, the inclusion of lagged fuel prices as a predictor substitutes other omitted and potentially unobservable predictor variables.

\footnotetext{
${ }^{9}$ Conventional market concentration indices like Herfindahl-Hirschmann Index (HHI) or concentration ratios $(\mathrm{CR})$ are not reported by each country. Nor are there enough data for own calculations. An attempt to proxy competition by checking the annual reports of these large companies for information on country specific turnover relative to a country's overall automotive fuel retail sales volume also failed due to limited data availability.

${ }^{10} \mathrm{In}$ order to indicate the relevance of predictors in determining fuel prices, we computed correlations using Spearman's $\rho$. For results, see Table 6 and Table 7 in the Appendix.
} 
Lagged prices are themselves driven by these predictors. Following the suggestion of Kaul et al. (2015), we include only the last pre-intervention period of 'gsprc' and 'dslprc' in the respective model. ${ }^{11}$

\section{Donor pool:}

A careful selection of suitable constituents of the donor pool is crucial: if countries that differ substantially from Austria both in terms of their outcome and predictor values are included, the synthetic control estimator is likely to be biased. Consequently, the estimated causal effect may poorly reflect the true effect of Austria's fuel price regulation on gasoline and diesel prices. Ultimately, eleven European countries are chosen to constitute the donor pool of our main specification. An alternative specification is based on a larger donor pool of 23 countries (results are reported in Subsection 4.2.3 and the Online Appendix to this paper).

On a global perspective, fuel prices in European countries are relatively high because these countries are not able to satisfy the demand for gasoline and diesel by means of domestic resources and therefore strongly depend on imports. Instead of considering all European countries, the analysis focuses on member states of the European Union, where we can assume a high degree of economic, and political cohesion rendering those states particularly suitable for the donor pool. ${ }^{12}$ Unfortunately, fuel prices are only available since 2005 for several countries. Note that fuel prices should be available during the entire time span $t=1, \ldots, T$ to later be able to conduct placebo tests. One possibility to keep these countries in the donor pool is to let the pre-intervention period span from 2005 until 2008. This was attempted in our alternative specification using a larger donor pool but comes at the cost of fewer predictor variables. Moreover, a pre-treatment period from 2005 until 2008 might be too short to argue that a good fit is attained systematically. Therefore, we decided to eliminate these countries in favor of the largest possible pre-intervention window, spanning from 2000 until 2008. The eliminated countries are those that joined the EU after the Eastern Enlargement: Cyprus, Estonia, Hungary, Latvia, Lithuania, Malta, Poland, Slovakia, Slovenia, and the Czech Republic. One may argue that most of these countries tend to still lag behind in terms of economic conditions and transport infrastructure, potentially rendering

\footnotetext{
${ }^{11}$ Including the last pre-intervention values of the fuel prices ensures a precise fit of the synthetic control at the treatment period. Moreover, one may think of an "Ashenfelter's dip"-type argument here: a treatment might be more likely to be triggered in period $t$ (2009 in our case) if the preceding period $t-1$ (2008 in our case) was an outlier. Hence, it is important to capture this particular lag.

${ }^{12}$ Because there are no data available over the sampling period for Bulgaria, Croatia, and Romania, the EU25 countries serve as a starting point, which is in line with Dewenter et al. (2017).
} 
them less attractive control countries. Furthermore, Greece is excluded due to missing data on some of the predictors.

Aside from a required similarity in the characteristics outlined in Section 3, Abadie (2019) points out several other prerequisites that countries have to fulfill in order to be eligible for the donor pool. It should be ensured that none of the countries have experienced profound idiosyncratic shocks like political instabilities or financial crises. To the best of our knowledge, this holds for all countries in the reduced donor pool. Note that the variable GDP growth rate should at least partially account for economic crises. Further, there should be no spillover effects, i.e., constituents of the donor pool should not be affected by Austria's fuel price regulation. Moreover, it is important to select only countries that are not exposed to a similar fuel price intervention. ${ }^{13}$ Consequently, Luxembourg and Belgium are excluded. Ultimately, the final donor pool consists of the following eleven control countries: Denmark, Finland, France, Germany, Ireland, Italy, the Netherlands, Portugal, Spain, Sweden, and the United Kingdom.

\subsection{Results}

\subsubsection{Effects on gasoline prices}

Figure 1 illustrates the yearly gasoline price series for Austria and its synthetic counterpart from 2000 to $2018 .{ }^{14}$ Note that the vertical line, indicating the fuel price intervention is drawn in 2008 instead of 2009. This is due to the fact that average prices for each year are calculated at the end of the year. However, the regulation was introduced in July of 2009 and is likely to have affected prices in the subsequent months. ${ }^{15}$ Before the Fuel Price Fixing Act was implemented in 2009, synthetic gasoline prices mimic those in the 'real' Austria closely. The pre-intervention RMSPE amounts to 0.92 Euro cents per liter. Compared with a pre-intervention average of 35.66 Euro cents per liter, the RMSPE suggests a precise fit. After the cut-off, paths start to diverge,

\footnotetext{
${ }^{13}$ We note that France (in 2007) and Germany (in 2013) passed similar laws on transparency of fuel prices (Montag and Winter, 2020). However, fuel prices in both countries are not regulated by Austrian-type fuel price interventions or other similar regulations like price floors or price ceilings.

${ }^{14}$ The following analysis is conducted using the $\mathrm{R}$ package 'Synth'. There are several other $\mathrm{R}$ packages available that implement various generalizations, e.g., allowing for multiple treated units, a simultaneous consideration of various outcomes of interest or the treatment of predictor variables as time series (see, e.g., 'gsynth' or 'MSCMT'). These features are not relevant for this study.

${ }^{15}$ Alternatively, one may drop observations for 2009 because it cannot be fully classified as a pre- or post-intervention year as suggested by Peri and Yasenov (2019). However, Wang (2009) finds that, in the case of Western Australia, changes in the price level are only observed within the first four months after its implementation. Therefore, observations for 2009 are not dropped.
} 
and the counterfactual trajectory remains above the observed prices during the entire post-intervention period. Table 1 reports the average pre-intervention values for each predictor. Comparing these values suggests that the synthetic control matches Austria fairly well. Note that urb cannot be closely fitted by a standard convex combination because Austria tends to have the lowest degree of urbanization between 2000 and 2008.

Table 2, listing the individual country weights, reveals that Germany accounts for the largest share (32.5\%) in the synthetic Austria, followed by Italy (31.1\%) and Ireland $(30.6 \%)$. While a contribution of Germany and Italy, as neighboring countries, appears to be plausible, the large share of Ireland, instead, may seem surprising. One might have rather expected that France or the Netherlands plays a larger role because both of them, like Austria, are transit countries. However, studying the descriptive statistics more closely reveals that Ireland has the almost identical degree of urbanization as Austria and a very low share of motorways, which helps to approximate Austria likewise having a below-average share of motorways (although much higher than Ireland). ${ }^{16}$

In total, the weighted average of the eleven donor pool countries outperforms the sample average for most variables. Altogether, Figure 1 and Table 1 suggest the synthetic control is a reasonable approximation to the gasoline prices that would have been set in Austria in the absence of the fuel price intervention of 2009.

Table 1 and Table 2 further illustrate an attractive feature of the SCM: as opposed to DiD designs for which predictors are not explicitly analyzed, but instead assumed to be similar under the parallel trends assumption, the SCM is more transparent in this regard. On the one hand, it reveals the discrepancy between the synthetic and treated unit, reflected by the difference between the first two columns in Table 1 . On the other hand, it explicitly shows the individual contribution of each control unit. Figure 2 highlights the contributing countries on a map of the European Union.

\footnotetext{
${ }^{16}$ To further investigate the importance of including Ireland in the weight matrix, we excluded Ireland and re-estimated the model. It turns out that our results based on this leave-one-out exercise do not change substantially.
} 
Figure 1: Austria versus synthetic control (gasoline)

This figure plots the gasoline prices for Austria and the synthetic control from 2000 to 2018.

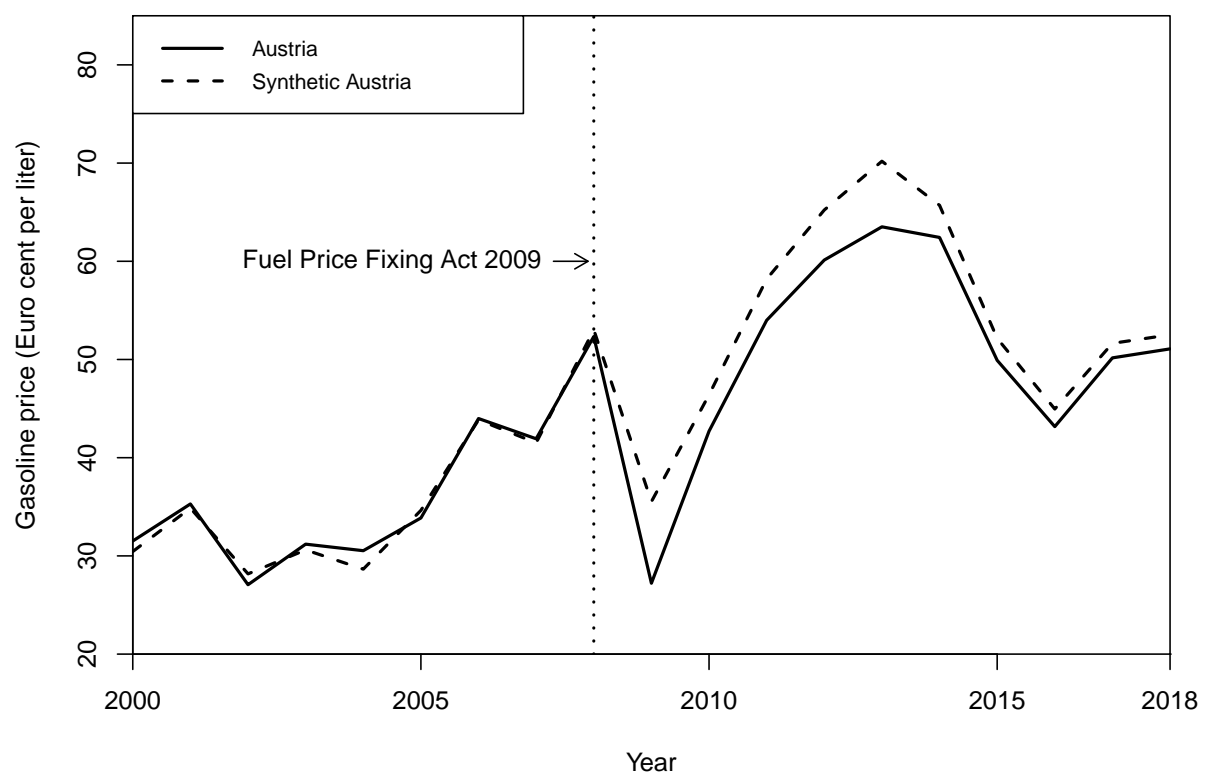

Table 1: Predictor means (gasoline)

\begin{tabular}{rrrr}
\hline & Austria & Synthetic & Sample Mean \\
\hline gdppc & 34385.69 & 33090.90 & 31818.31 \\
mgcpc & 0.25 & 0.31 & 0.29 \\
psngrcrs & 503.75 & 502.88 & 450.48 \\
crd & 48.85 & 47.86 & 47.44 \\
urb & 59.09 & 67.72 & 75.28 \\
gsprc & 52.34 & 53.02 & 52.94 \\
rddnsty & 129.46 & 125.37 & 140.72 \\
mtrwys & 1.58 & 2.70 & 3.20 \\
\hline
\end{tabular}

This table shows the predictor means of Austria, the sample mean over the donor pool, and the synthetic control from 2000 to 2008. The variable codes are 'gdppc': GDP per capita (in euros), 'mgcpc': per capita motor gasoline consumption in road (in tons), 'psngrcrs': passenger cars per one thousand inhabitants, 'crd': crude oil import prices (in USD), 'urb': urbanization (in \% of total population), 'gsprc': gasoline prices (Euro cents per liter), 'rddnsty': density of road (km per $\left.100 \mathrm{~km}^{2}\right)$, 'mtrwys': share of motorways in total road network (in \%). 


\section{Table 2: Country weights (gasoline)}

\begin{tabular}{rr}
\hline country & weight \\
\hline denmark & 0.0 \\
finland & 0.0 \\
france & 1.4 \\
germany & 32.5 \\
ireland & 30.6 \\
italy & 31.1 \\
the netherlands & 0.0 \\
portugal & 4.1 \\
spain & 0.2 \\
sweden & 0.0 \\
uk & 0.0 \\
\hline
\end{tabular}

This table lists the weights for the donor pool countries (in \%) used to construct the synthetic control for the gasoline model.

The estimated effect of Austria's fuel price intervention can be measured as a function of the difference between Austria and its synthetic counterpart. Figure 3 reveals that the effect is largest immediately after the implementation. Gasoline prices are substantially lower at the end of 2009. While the counterfactual predicts a gasoline price of 35.50 Euro cents per liter, the observed price amounts to 27.22 Euro cents. Thus, the Fuel Price Fixing Act seems to have led to a decline in yearly gasoline prices by 8.31 Euro cents in the short-run, which is equivalent to $23.4 \%$. Until the end of 2010, the gap tightens again, leaving a difference of 3.70 Euro cents per liter. This finding is in line with Wang (2009), who concludes that an effect of a similar intervention implemented in Western Australia affects prices only for four months before they rise again.

The revision of the Fuel Price Fixing Act and the Law on Transparency of Fuel Prices came into effect in January 2011 and August 2011, respectively. The gap widens again at the end of 2011 and the effect appears to be prevalent until 2013. By the end of 2013, the observed gasoline price is 6.68 Euro cents lower than the counterfactual. Because two policy changes occur in 2011, and another slight revision of the Fuel Price Fixing Act was enacted in 2012, we cannot attribute the widening of the gap clearly to either one of these changes. However, because the revision of the Fuel Price Fixing Act in 2011 only unifies the time for price increases across different types of filling stations and the revision of 2012 freezes prices over selected weekends, it seems to be more likely 
Figure 2: Composition of synthetic Austria (gasoline)

This figure highlights countries contributing to the synthetic control for gasoline prices. Austria is marked in black.

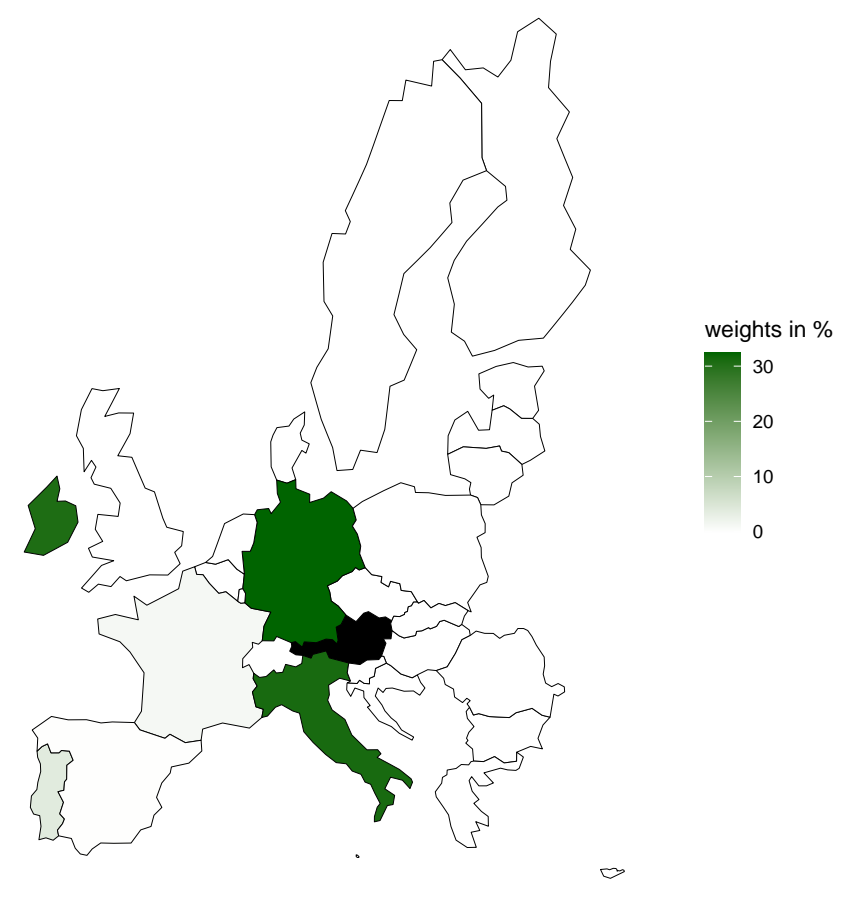

that lowering the search costs for consumers again by requiring retailers to submit their prices to an online platform, as outlined in the Law on Transparency of Fuel Prices, is responsible for another reduction of gasoline prices. However, we need to be careful when interpreting the effects of the Law on Transparency of Fuel Prices because the synthetic control is constructed with regard to estimating causal effects of the Fuel Price Fixing Act. Hence, the choice of donor pool countries would need to change to properly estimate the effects of this policy, for example, by excluding France where a similar law is in effects since 2007. The 2012 revision of the Fuel Price Fixing Act still applies today. Here, the question arises why Austria's gasoline price increase again after 2013 and do not stay at their lower level. The average long-run effect over the period from 2009 to 2018 is a reduction in gasoline price levels of $7.5 \%$. For the case of 
Western Australia, Wang (2009) argues that the regulation impedes price coordination among firms in the short-run. After a few months, firms learn how to coordinate again, ultimately leading to higher prices. It appears that retailers have adjusted to the new market structure. Unfortunately, the available data do not allow us to investigate the individual decision process of retailers.

Figure 3: Effect on gasoline prices

This figure plots difference in gasoline prices. The gap is calculated as observed gasoline prices minus counterfactual gasoline prices.

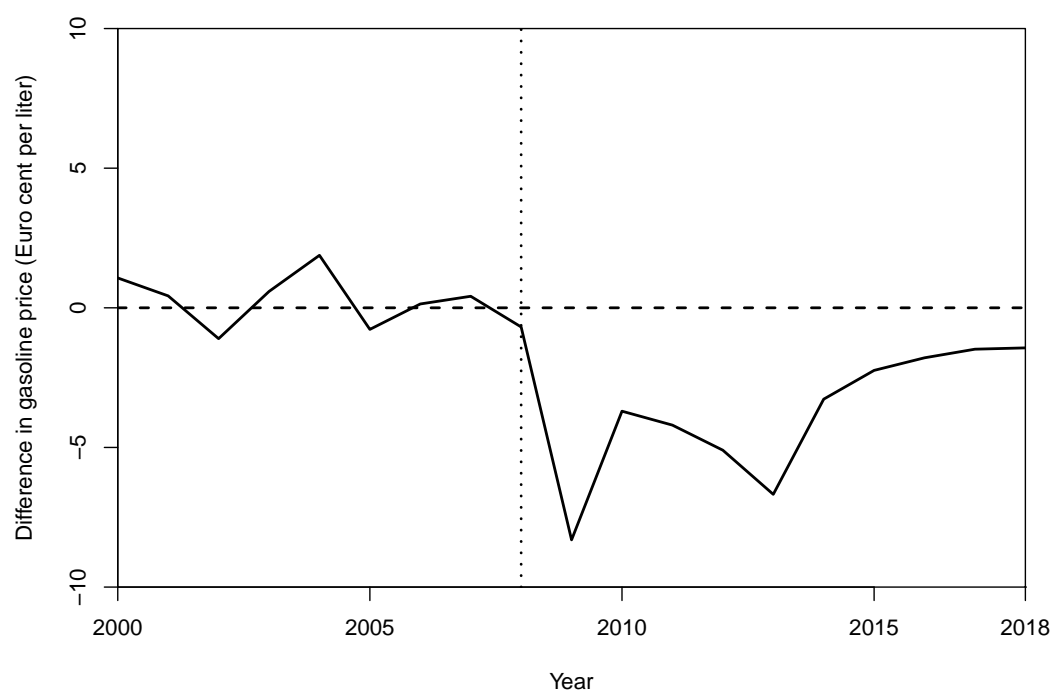

Because the interpretation of long-run effects is difficult in our setting with clustered policy changes in our post-treatment period, we focus on the interpretation of short-run effects. Before being able to truly claim that the Fuel Price Fixing Act in 2009 indeed lowered Austria's retail gasoline prices in the short-run, the credibility of estimates has to be further assessed. To do so, we conduct placebo-in-space tests as proposed by Abadie et al. (2010). The SCM is iteratively run on each donor pool country, pretending the respective country was the treated one. ${ }^{17}$ Then, post-intervention RMSPEs are compared with the pre-intervention RMSPEs. Figure 4 depicts the ratio for each country. It turns out that the ratio is largest for Austria. While the pre-RMSPE amounts to 0.92 , the post-RMSPE amounts to 4.87. Consequently, the post-intervention gap is more than five times larger than the pre-intervention gap. Following Abadie et al.

\footnotetext{
${ }^{17}$ Note that, as a treated country, Austria is excluded from the donor pool for our placebo-in-space tests.
} 
(2015), if one was to randomly select one of these twelve countries, the chances to obtain a ratio as high as 5.28 amounts to $1 /(J+1)$, thus to $1 / 12=0.08$. This procedure requires a large number of donor pool countries to obtain inferential statements. ${ }^{18}$

\section{Figure 4: Ratio of post-RMSPE to pre-RMSPE (gasoline)}

This figure ranks countries by its ratio of post-RMSPE to pre-RMSPE obtained from placebo-in-space tests.

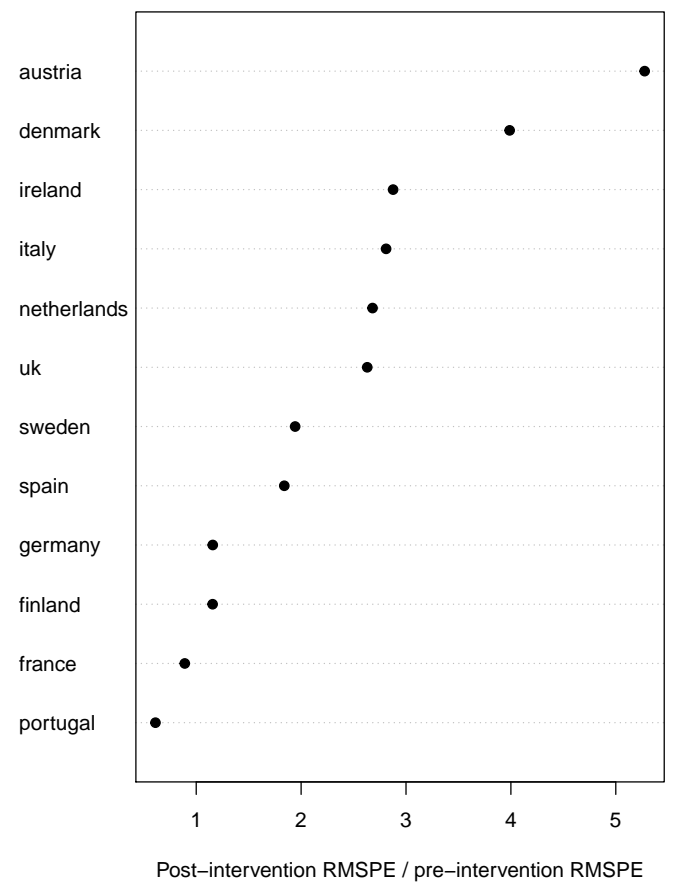

To further illustrate Austria's gasoline path behaving notably different from the other donor pool countries' paths, we plot the gaps for Austria and the respective placebo effects in Figure 5. Note that, for some countries, the synthetic control fails to precisely reproduce gasoline prices in the pre-intervention period. We therefore decide to exclude all countries with a pre-RMSPE three times larger than Austria's pre-RMSPE for this exercise. In the gasoline model, this threshold is exceeded by Portugal only. Its pre-RMSPE is more than eight times larger than Austria's pre-RMSPE, indicating a rather bad pre-treatment fit. Portugal exhibits some extreme values in the predictor

\footnotetext{
${ }^{18}$ Due to limited data availability, the SCM can be run for the maximum number of donor pool countries only if the pre-intervention period is reduced to 2005-2008 and if some predictors are eliminated. The results are qualitatively similar, with Austria having the largest post-intervention gap and the chance under random selection amounts to $1 / 23=0.043$ in this case.
} 
variables such that no convex combination of donor pool countries is able to reproduce its gasoline price path. Figure 5 therefore depicts the gaps for Austria and the placebo effects for each donor pool country except for Portugal. The red line indicates the effect for Austria, the gray lines reflect the difference in gasoline prices between each donor pool country and its synthetic counterpart. The change in gasoline price can be ascribed to the intervention only if the estimated effect for Austria is large relative to the distribution of placebo effects. Among those countries whose synthetic control provides a good fit, the negative effect is largest for Austria during the first four years after the intervention. The effect seems to dissipate after 2013.

Figure 5: Placebo effects (gasoline)

This figure plots the placebo effects for each country (except for Portugal) obtained from placebo-inspace tests. Portugal is excluded due to a high pre-RMSPE.

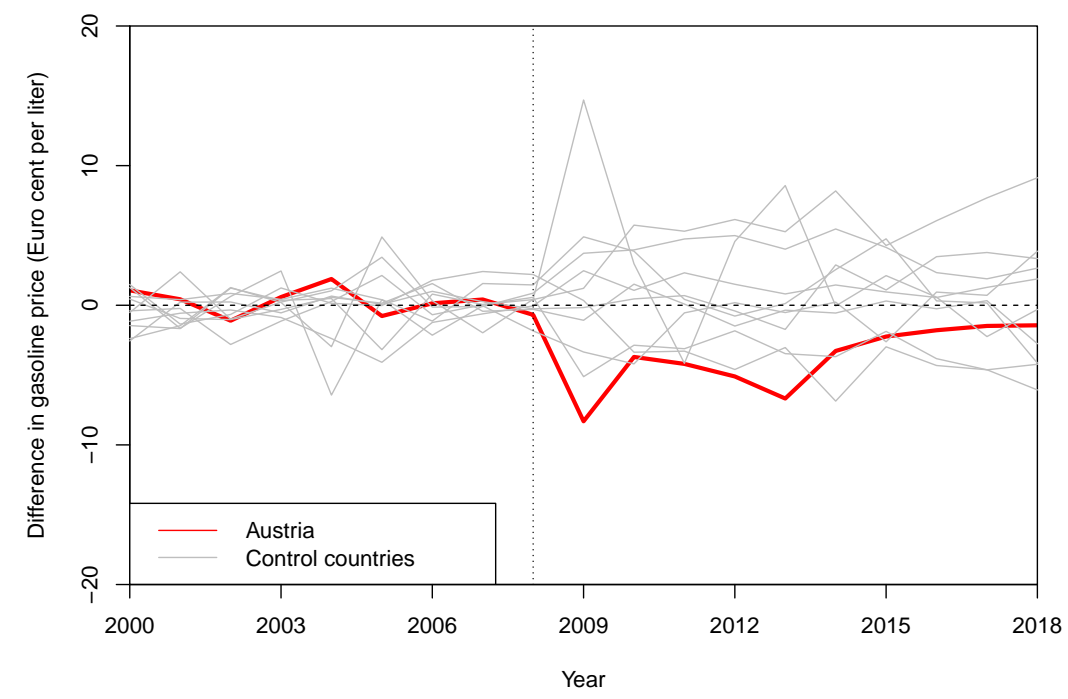

Abadie et al. (2010) also discuss running placebo-in-time tests, pretending the intervention was implemented earlier. Here, this would result in a shorter pre-intervention period and is therefore not attempted. 


\subsubsection{Effects on diesel prices}

Figure 6 plots the yearly diesel prices for Austria and its synthetic control from 2000 to 2018. Similar to the gasoline model, the synthetic control closely reproduces the price series before the intervention. The pre-RMSPE amounts to 0.97 Euro cents per liter. Given an average of 39.96 Euro cents per liter, the fit is as precise as in the gasoline model. However, the divergence after the implementation of the Fuel Price Fixing Act in 2009 is clearly less pronounced. The counterfactual trajectory only slightly exceeds the observed diesel prices.

Figure 6: Austria versus synthetic control (diesel)

This figure plots the diesel prices for Austria and the synthetic control from 2000 to 2018.

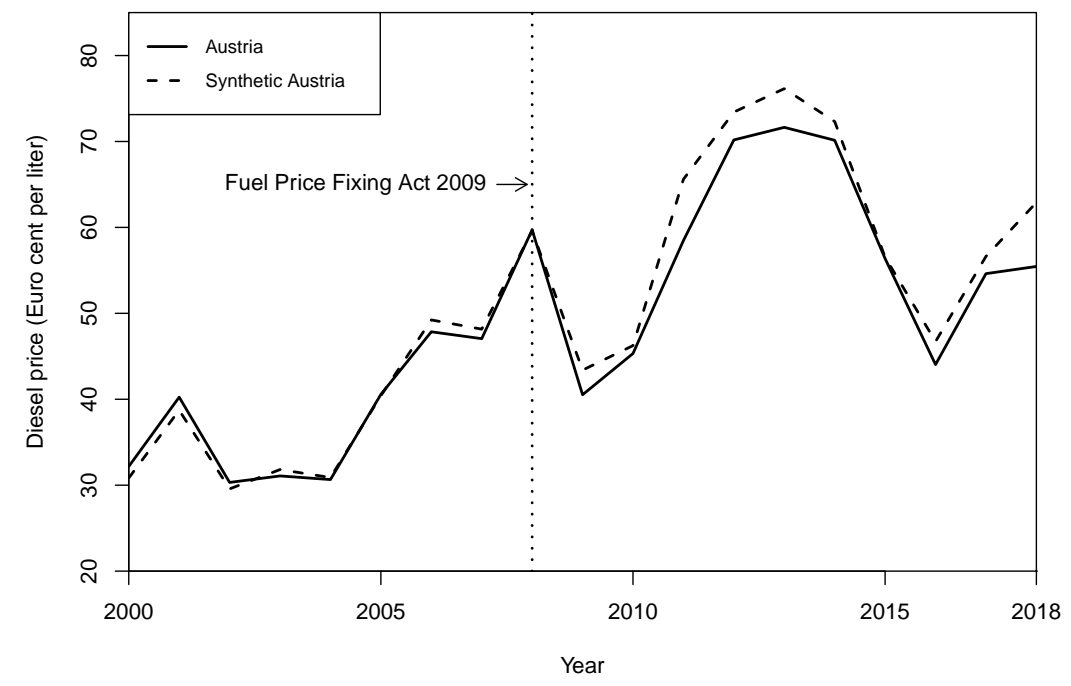

Table 3 reveals that the synthetic control achieves a good fit for most predictor variables. Diesel consumption per capita, $d c p c$, tends to be largest in Austria, rendering a close match based on a standard convex combination difficult. The estimated value for crude oil import prices, $c r d$, is slightly worse than the sample mean. Crude oil import prices tend to be lowest in the Netherlands, which could be explained by the presence of the Antwerp-Rotterdam-Amsterdam (ARA) oil refining complex. The Netherlands may therefore have a cost advantage over other European countries. As shown in Table 4, the Netherlands contribute to constructing the synthetic control by more than $15 \%$. 


\section{Table 3: Predictor means (diesel)}

\begin{tabular}{rrrr}
\hline & Austria & Synthetic & Sample Mean \\
\hline gdppc & 34385.69 & 33942.87 & 31818.31 \\
dcpc & 0.61 & 0.35 & 0.39 \\
psngrcrs & 503.75 & 486.95 & 450.48 \\
crd & 48.85 & 46.93 & 47.44 \\
urb & 59.09 & 77.73 & 75.28 \\
gdpgrwth & 2.32 & 2.33 & 2.41 \\
dslprc & 59.72 & 59.59 & 60.11 \\
rddnsty & 129.46 & 132.76 & 140.72 \\
gdsvhcl & 5.87 & 8.36 & 15.46 \\
mtrwys & 1.58 & 1.69 & 3.20 \\
\hline
\end{tabular}

This table shows the predictor means of Austria, the sample mean over the donor pool, and the synthetic control from 2000 to 2008. The variable codes are 'gdppc': GDP per capita (in euros), 'dcpc': per capita diesel oil consumption in road (in tons), 'psngrcrs': passenger cars per one thousand inhabitants, 'crd': crude oil import prices (in USD), 'urb': urbanization (in \% of total population), 'gdpgrwth': GDP growth rate (in \%), 'dslprc': diesel prices (Euro cents per liter), 'rddnsty': density of road (km per $100 \mathrm{~km}^{2}$ ), 'gdsvhcl': share of goods road motor vehicles in total road motor vehicles (in \%), 'mtrwys': share of motorways in total road network (in \%).

Table 4: Country weights (diesel)

\begin{tabular}{rr}
\hline country & weight \\
\hline denmark & 0.0 \\
finland & 0.0 \\
france & 0.0 \\
germany & 14.6 \\
ireland & 0.6 \\
italy & 20.6 \\
the netherlands & 15.4 \\
portugal & 0.0 \\
spain & 0.0 \\
sweden & 43.4 \\
uk & 0.0 \\
\hline
\end{tabular}

This table lists the weights for the donor pool countries (in \%) used to construct the synthetic control for the diesel model.

Table 4 reveals that Italy again accounts for a large share $(20.6 \%)$ in the synthetic control. Compared with the gasoline model, Germany loses importance while Ireland becomes almost irrelevant for predicting diesel prices. Instead, Sweden accounts for 
the largest share (43.4\%). The large share for Sweden can partly be attributed to the inclusion of the 'share of goods road motor vehicles in total road motor vehicles' and 'diesel prices' variables for which Austria and Sweden have similar pre-treatment averages. In Figure 7, the contributing countries are highlighted on a map of the European Union.

Figure 7: Composition of synthetic Austria (diesel)

This figure highlights countries contributing to the synthetic control for diesel prices. Austria is marked in black.

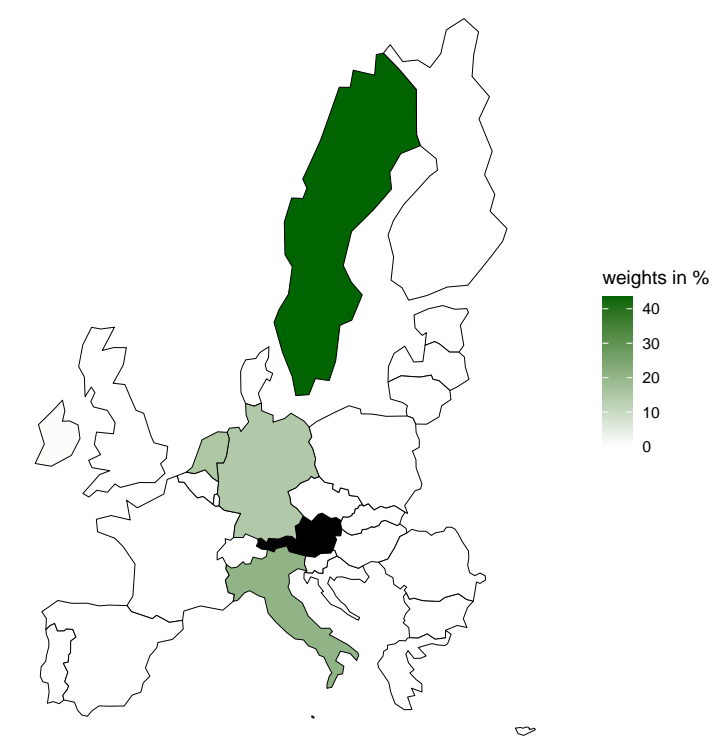

Clearly, one cannot directly compare the two fuel price models with respect to the control countries because the chosen predictors differ. What can be compared is the size of the effect. This is because both synthetic fuel paths exhibit a similar degree of fit in terms of the pre-intervention RMSPE relative to their pre-intervention price average. The negative effect on diesel prices immediately after the intervention is small. While the counterfactual predicts a diesel price of 43.39 Euro cents per liter, the observed price amounts to 40.52 Euro cents. By the end of 2009, the yearly diesel price is thus 2.87 Euro cents lower as can be seen in Figure 8. Interestingly, this corresponds to the result of Dewenter et al. (2017), predicting a decrease of 2 to 4 Euro cents. While the gasoline price falls by $23.4 \%$ in the short-run, the diesel price appears to be less 
affected by the intervention, decreasing by only $6.6 \%$. Like in the gasoline model, the gap of diesel temporarily narrows in 2010. By the end of 2011, the difference between Austria and its counterfactual reaches its maximum. Austria's diesel price is predicted to amount to 65.60 Euro cents in the absence of the intervention, and the observed price lies 7.13 Euro cents below, suggesting a drop by $10.9 \%$. The average long-run effect for diesel prices over the period from 2009 to 2018 is a reduction of $5.4 \%$, but again we need to be cautious interpreting this estimate and cannot attribute this effect only to the Fuel Price Fixing Act of 2009.

Figure 8: Effect on diesel prices

This figure plots difference in diesel prices. The gap calculated as observed diesel prices minus counterfactual diesel prices.

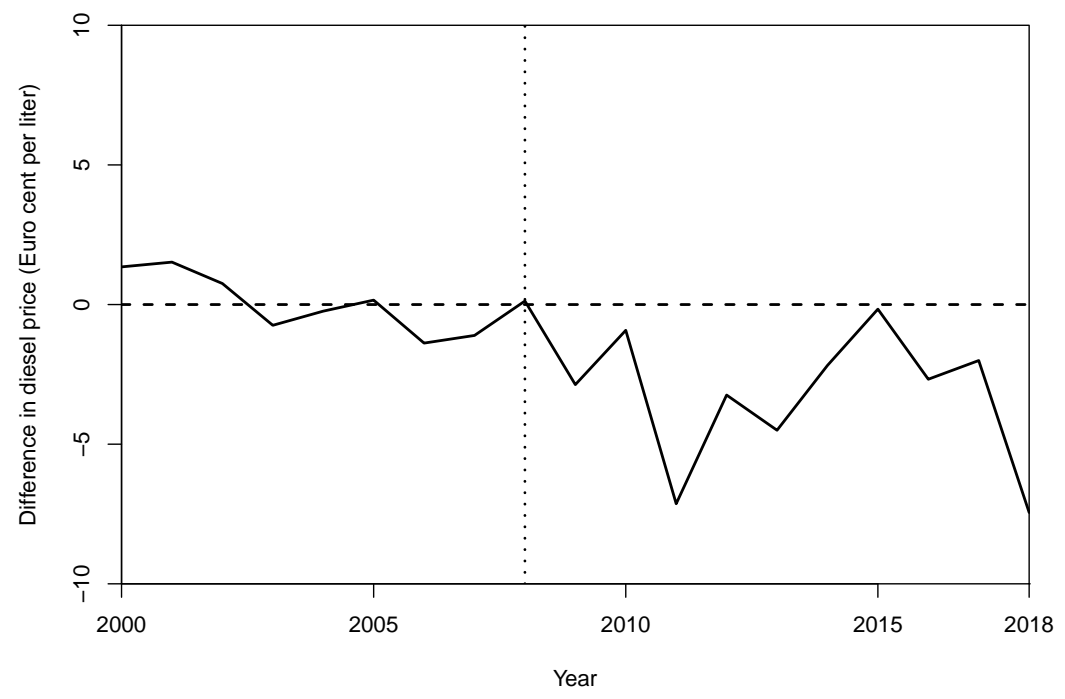

Figure 9 plots the gaps for Austria and the placebo effects for the donor pool countries. Again, we decide to exclude all countries with a pre-RMSPE three times larger than Austria's pre-RMSPE. In the diesel model, this threshold is exceeded by Portugal and Italy. Interestingly, the price effect for Austria does not seem to be notably different compared with the other donor pool countries. This raises the question as to whether the effect on Austria's diesel prices is significant at all. 
Figure 9: Placebo effects for (diesel)

This figure plots the placebo effects for the each country (except for Italy and Portugal) obtained from placebo-in-space tests. Italy and Portugal are left out due to a high pre-RMSPE.

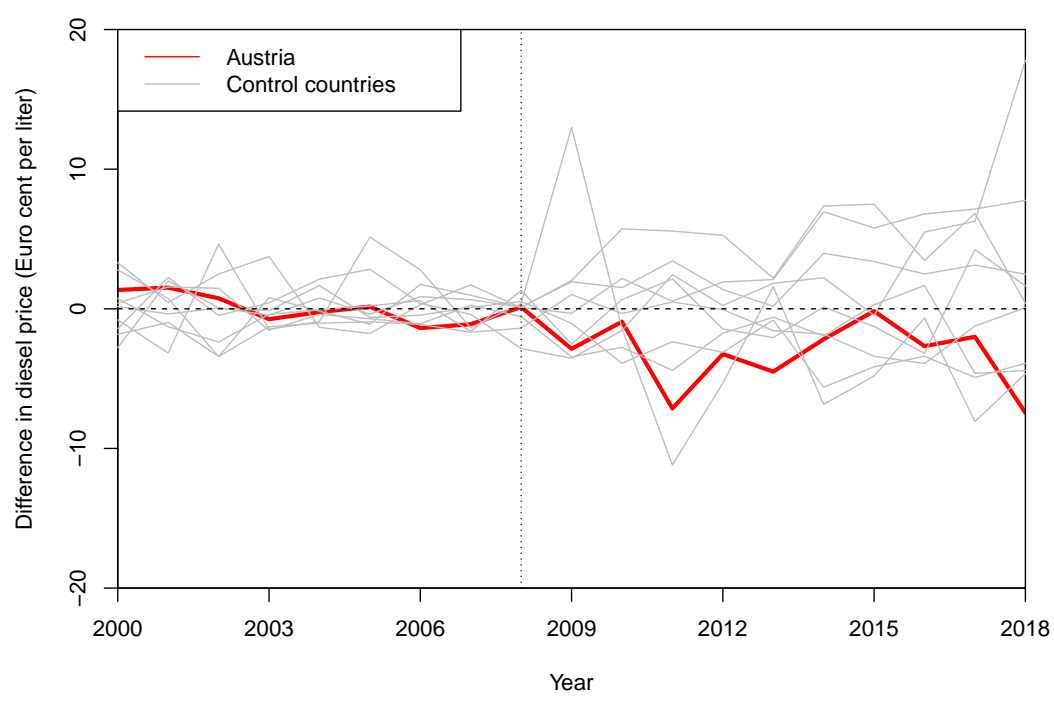

This finding is further emphasized by Figure 10, which shows that the post-RMSPEpre-RMSPE ratio is largest for the Netherlands. The pre-intervention RMPSE for the Netherlands amounts to 0.65, thereby outperforming the fit of the synthetic Austria. Consequently, the chance to obtain an effect at least as large as in Austria is 2/12= 0.16. Diesel is predominantly consumed by commercial users in goods transport, heavy machinery, and the building sector. They typically buy larger quantities more frequently and thus have greater incentive to expend resources searching for lower prices (Johnson, 2002). Large trucking firms closely monitor diesel prices at a national and local level and direct their trucks to particular fueling locations. Presumably, these users had already searched intensively for the cheapest price before the intervention. Therefore, improving transparency through limiting retailer's pricing strategies may not change their behavior such that the degree of competition in this market is less affected and prices are thus less responsive. In general, Wadud (2016) finds that diesel prices are quite inelastic. Moreover, because the overall demand for diesel is driven by various sectors, regulations tackling only retail diesel prices at filling stations could be less effective. 
Figure 10: Ratio of post-RMSPE to pre-RMSPE (diesel)

This figure ranks countries by its ratio of post-RMSPE to pre-RMSPE obtained from placebo-in-space tests.

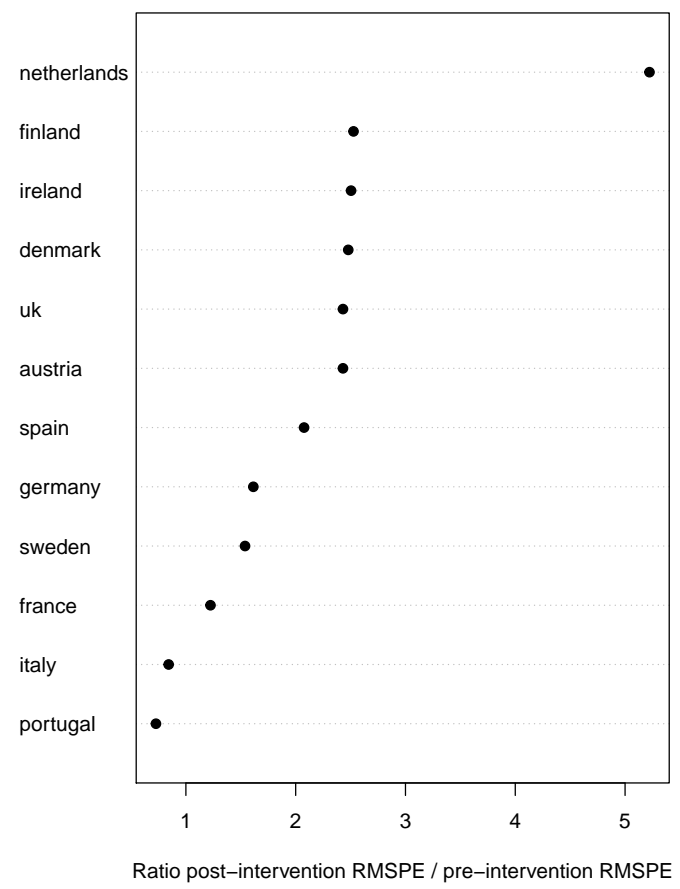

\subsubsection{Robustness checks}

In the following, we present a summary of our robustness checks. We evaluate the sensitivity of our main results to certain aspects of our model specification. To conserve space, we report the corresponding figures and tables in the Online Appendix to this paper.

First, we discuss the results for a specification with a larger donor pool of 23 countries, but a shorter pre-intervention period and fewer predictor variables. Particularly, the latter shortcoming is problematic considering that the estimate of our causal effects improves with the number of pre-intervention periods (Abadie et al., 2010). However, including more pre-treatment periods and a larger set of predictor variables is not possible due to data being unavailable for the larger donor pool. The gasoline model includes $g d p p c, m g c p c$, urb, and pre-treatment gasoline prices from 2008 as predictor variables. In contrast to our main specification, we find different weights to construct the synthetic control, for example, Slovakia receiving a large weight at the expense of Germany 
and Italy. However, the estimated short-run effects remain qualitatively similar with a reduction of $26.4 \%$, and the average long-run effects yields the identical reduction of 7.5\%. For the diesel model, we use the predictor variables gdppc, urb, gdpgrwth, and diesel prices from 2008. In this specification, France and Ireland receive large weights. Again, the short-run effect $(-18.7 \%)$ are larger than in the main specification, but the average long-run effects $(-3.5 \%)$ are robust.

Second, we use fuel prices, including tax and duty, comparing those results with the estimates for our main results involving net prices. The short-run effect for the gasoline model amounts to a reduction of 13.43 Euro cents which is larger than the short-run effect for the main specification (8.31 Euro cents), but in percentage terms, the effect is smaller (12.9\% versus $23.4 \%$ ). For the diesel model, we do not report a substantial effect of the Fuel Price Fixing Act. The short-run effect is zero and the long-run effect amounts to a very slight reduction of $0.3 \%$. Using fuel prices, including tax and duty, we still find a heterogeneous effect across fuel markets.

Third, we perform a placebo-in-variable test and re-estimate our main specification for heating oil taking the role of the dependent variable. Heating oil prices are also obtained from the DG ECFIN. Like gasoline and diesel, heating oil is another retail petroleum product (often chemically identical to diesel), but its market is not subject of the Fuel Price Fixing Act. Consequently, we can test with this specification if our selection of predictor variables and donor pool countries a priori influences our results. Because the set of predictor variables differs between the gasoline and the diesel specifications, we estimate the heating oil model for both sets of predictor variables. Using the gasoline specification, we find short-run effects of $+4.0 \%$ and long-run effects of $+1.2 \%$ on heating oil prices. Similarly, the diesel specification yields short-run effects of $+0.2 \%$ and long-run effects of $-0.5 \%$. We conclude that the Fuel Price Fixing Act does not have a substantial effect on Austria's heating oil prices.

Fourth, we further strengthen the credibility of our results by leaving out specific donor pool countries. Evaluating these leave-one-out tests helps us rule out the possibility that our results are driven by a certain country. Due to its institutional similarity and its high weight, Germany appears to be a potential driver. However, when excluding Germany from the donor pool, the leave-one-out synthetic control still closely matches the baseline synthetic Austria, verifying the robustness of our results. ${ }^{19}$

\footnotetext{
${ }^{19}$ In addition, we estimated two further variants. In the first specification, we left out France and in the second, we left out both France and Germany at the same time. Both countries passed laws on transparency of fuel prices during our sample period. Our results still remain robust.
} 


\section{Conclusion and policy implications}

In this study, we examine the price effects of the Austrian Fuel Price Fixing Act applying the SCM. The Austrian fuel price intervention in 2009 primarily aims at improving transparency. Previous studies relate transparency on fuel price markets to the search cost theory, suggesting that transparency increases competition, which ultimately results in lower retail prices. Motivated by these findings, we empirically investigate whether Austria's fuel price intervention lowered gasoline and diesel price levels. The results suggest a negative effect for gasoline throughout the entire post-intervention period from 2009 to 2018. The effect is largest immediately after the implementation of the Fuel Price Fixing Act in 2009. Compared with the counterfactual, the yearly gasoline price in 2009 is estimated to be lower by $23.4 \%$. The effect appears to dissipate in the following year before it increases again in 2011, presumably as a result of the Law in Transparency of Fuel Prices, enacted in August 2011. In contrast, the effect on diesel prices seems to be less pronounced. Because the pre-intervention fit between Austria's diesel prices and their synthetic version is almost identical to the gasoline model, the effects are directly comparable. In addition, placebo-in-space tests reveal that the effect on diesel is not largest in a set of control countries that have not been exposed to an intervention. This provides evidence against a significant effect on the diesel price level. These heterogeneous results for gasoline and diesel are in contrast to the findings of Dewenter et al. (2017), who predict both fuel prices to equally decrease by 2 to 4 Euro cents. However, both empirical studies agree that Austria's fuel price regulation does not necessarily lead to higher retail fuel prices, a prediction made by several theoretical and lab-experimental studies (Berninghaus et al., 2012; Haucap and Müller, 2012; Obradovits, 2014; Angerer, 2019).

Limited data availability is a major constraint for the application of SCM in our setting. Extensive placebo-in-time tests and some cross-validation procedures cannot be applied due to the short pre-intervention period. A general limitation of SCM is its inability to quantify uncertainty as a result of the quasi-experimental setting and small samples. The permutation strategy suggested by Abadie et al. (2010) must not be interpreted as a tool to provide a sampling distribution of test statistics. The chance of obtaining a ratio of post-RMSPE to pre-RMSPE as large as that of the treated unit does not provide evidence against a null hypothesis and hence should not be interpreted as a statistical test. However, it still answers the question of how often we would obtain a price effect as large as that of the treatment country if we had chosen a country at 
random.

Price levels react strongly (at least for gasoline) after the initial fuel price intervention in 2009 and again in 2011. Although we estimate quite large short-term effects of the price regulation for gasoline, our dynamic treatment effects imply that the Fuel Price Fixing Act has substantially smaller long-term effects on the price levels of both fuel markets. It seems that price levels decrease if the tacit collusion equilibrium is perturbed. Prices increase again after the retailers have adjusted to the new pricing regime and a new equilibrium has been found. In contrast to Andreoli-Versbach and Franck (2015), we find positive effects of a sticky pricing strategy as long as it is imposed by a fuel price regulation. The important difference between the analyzed policies is that one entails a new federal regulation for all retailers, whereas the other is a unilateral announcement of a pricing strategy by a single large company.

Comparing our results with those discussed in prior empirical studies, also taking into account the predictions made from theoretical and lab-experimental settings, we conclude that the effects of fuel price regulations depend strongly on the nature of the specific regulation and on the existing market structure. Policy makers should consider potentially negative effects, for example, less efficient prices harming consumer welfare, when dealing with recurring public discussions about stricter fuel price regulations. Future research could focus on a comprehensive empirical analysis of regulated fuel markets to find out which factors contribute to the success of those regulations.

\section{Acknowledgement}

We thank Robert Jung and Alexander Schmidt for helpful comments and suggestions. Access to Thomson Reuters Datastream, provided by the Hohenheim Datalab (DALAHO), is gratefully acknowledged. 


\section{A Data}

Table 5: Variables and data sources

\begin{tabular}{|c|c|c|}
\hline Variable & Explanation and data availability & Source \\
\hline gsprc & $\begin{array}{l}\text { Gasoline price, originally quoted in } € \text { per } 1000 \text { liter. Transformed to obtain gasoline } \\
\text { price in Euro cents per liter. }\end{array}$ & $\begin{array}{l}\text { Directorate General for Economic and Fi- } \\
\text { nancial Affairs (DG ECFIN), retrieved via } \\
\text { Thomson Reuters Datastream }\end{array}$ \\
\hline dslprc & $\begin{array}{l}\text { Diesel price, originally quoted in } € \text { per } 1000 \text { liter. Transformed to obtain diesel } \\
\text { price in Euro cents per liter. }\end{array}$ & $\begin{array}{l}\text { Directorate General for Economic and Fi- } \\
\text { nancial Affairs (DG ECFIN), retrieved via } \\
\text { Thomson Reuters Datastream }\end{array}$ \\
\hline mgcpc & $\begin{array}{l}\text { Motor gasoline consumption in road, quoted in tons used in vehicles on public roads. } \\
\text { Vehicles used primarily in agriculture, for military or on industrial sites are excluded. } \\
\text { Manually divided by population size. Data availability: } 2000-2008 \text {. }\end{array}$ & $\begin{array}{l}\text { United Nations, Energy Statistics Database; } \\
\text { The World Bank, World Development Indi- } \\
\text { cators (population size) }\end{array}$ \\
\hline crd & $\begin{array}{l}\text { Crude oil import prices, including cost, insurance and freight Quoted in US Dollar } \\
\text { per barrel. Data availability: } 2000-2008 \text {. }\end{array}$ & OECD, International Energy Agency \\
\hline rddnsty & $\begin{array}{l}\text { Density of road, quoted in kilometers per one hundred square kilometers. Data } \\
\text { availability: } 2006-2007 \text {. }\end{array}$ & OECD, Transport Performance Indicators \\
\hline gdppc & GDP per capita, PPP (current international \$). Data availability: 2000-2008. & $\begin{array}{l}\text { The World Bank, World Development Indi- } \\
\text { cators }\end{array}$ \\
\hline psngrers & $\begin{array}{l}\text { Road motor vehicles such as passenger cars, taxis, ambulances, hire cars and vans } \\
\text { primarily intended for the transport of passengers. Buses or other vehicles with } \\
\text { more than nine seats are excluded. Not differentiated by fuel type. Data availability: } \\
\text { 2000-2008. }\end{array}$ & OECD, Transport Performance Indicators \\
\hline mtrwys & Share of motorways in total road network. Data availability: $2006-2007$. & OECD, Transport Performance Indicators \\
\hline urb & $\begin{array}{l}\text { Share of people living in urban areas (percentage of total population). Data avail- } \\
\text { ability: 2000-2008. }\end{array}$ & $\begin{array}{l}\text { The World Bank, World Development Indi- } \\
\text { cators }\end{array}$ \\
\hline dcpc & $\begin{array}{l}\text { Diesel consumption in road, quoted in tons used in vehicles on public roads. Vehi- } \\
\text { cles used primarily in agriculture, for military or on industrial sites are excluded. } \\
\text { Manually divided by population size. Data availability: } 2000-2008 \text {. }\end{array}$ & $\begin{array}{l}\text { United Nations, Energy Statistics Database, } \\
\text { The World Bank, World Development Indi- } \\
\text { cators (population size) }\end{array}$ \\
\hline gdsvhcl & $\begin{array}{l}\text { Lorries, vans, pick-ups, heavy goods road vehicles above } 3.5 \text { tons as well as road and } \\
\text { agricultural tractors allowed to use public roads and designed to carry goods. Data } \\
\text { availability: } 2000-2004 \text {. }\end{array}$ & OECD, Transport Performance Indicators \\
\hline gdpgrwth & $\begin{array}{l}\text { Annual growth rate of GDP at market prices based on constant local currency. } \\
\text { Aggregates are based on constant } 2010 \text { US } \$ \text {. Data availability: 2000-2008. }\end{array}$ & $\begin{array}{l}\text { The World Bank, World Development Indi- } \\
\text { cators }\end{array}$ \\
\hline
\end{tabular}




\section{B Additional tables}

\section{Table 6: Correlations between predictors and gasoline prices}

\begin{tabular}{rc}
\hline Predictors & Correlations \\
\hline gdppc & -0.22 \\
mgcpc & $-0.50^{* *}$ \\
psngrcrs & $-0.50^{* *}$ \\
crd & 0.36 \\
urb & $-0.57^{* *}$ \\
rddnsty & $-0.31^{* *}$ \\
mtrwys & 0.12 \\
\hline
\end{tabular}

This table shows cross-sectional correlations between predictor variables and gasoline prices. Predictors are averaged over the pre-intervention period from 2000 to 2008. Correlations are calculated by means of Spearman's $\rho$. A pair-wise bootstrap with 400 replications is employed to compute standard errors. The variable codes are 'gdppc': GDP per capita (in euros), 'mgcpc': per capita motor gasoline consumption in road (in tons), 'psngrcrs': passenger cars per one thousand inhabitants, 'crd': crude oil import prices (in USD), 'urb': urbanization (in \% of total population), 'rddnsty': density of road $\left(\mathrm{km}\right.$ per $\left.100 \mathrm{~km}^{2}\right)$, 'mtrwys': share of motorways in total road network (in \%).

\section{Table 7: Correlations between predictors and diesel prices}

\begin{tabular}{rc}
\hline Predictors & Correlations \\
\hline gdppc & 0.31 \\
dcpc & 0.08 \\
psngrcrs & -0.14 \\
crd & 0.32 \\
urb & -0.19 \\
gdpgrwth & $-0.49^{* * *}$ \\
rddnsty & $-0.28^{* *}$ \\
gdsvhcl & $-0.53^{* *}$ \\
mtrwys & -0.30 \\
\hline
\end{tabular}

This table shows cross-sectional correlations between predictor variables and diesel prices. Predictors are averaged over the pre-intervention period from 2000 to 2008. Correlations are calculated by means of Spearman's $\rho$. A pair-wise bootstrap with 400 replications is employed to compute standard errors. The variable codes are 'gdppc': GDP per capita (in euros), 'dcpc': per capita diesel oil consumption in road (in tons), 'psngrcrs': passenger cars per one thousand inhabitants, 'crd': crude oil import prices (in USD), 'urb': urbanization (in \% of total population), 'gdpgrwth': GDP growth rate (in \%), 'rddnsty': density of road $\left(\mathrm{km}\right.$ per $\left.100 \mathrm{~km}^{2}\right)$, 'gdsvhcl': share of goods road motor vehicles in total road motor vehicles (in \%), 'mtrwys': share of motorways in total road network (in \%). 


\section{References}

Abadie, A., 2019. Using synthetic controls: Feasibility, data requirements, and methodological aspects. Journal of Economic Literature Forthcoming.

Abadie, A., Diamond, A., Hainmueller, J., 2010. Synthetic control methods for comparative case studies: Estimating the effect of California's tobacco control program. Journal of the American Statistical Association 105, 493-505. doi:10.1198/jasa.2009.ap08746.

Abadie, A., Diamond, A., Hainmueller, J., 2015. Comparative politics and the synthetic control method. American Journal of Political Science 59, 495-510. doi:10.1111/ajps.12116.

Abadie, A., Gardeazabal, J., 2003. The economic costs of conflict: A case study of the Basque Country. American Economic Review 93, 113-132. doi:10.1257/000282803321455188.

Alm, J., Sennoga, E., Skidmore, M., 2009. Perfect competition, urbanization, and tax incidence in the retail gasoline market. Economic Inquiry 47, 118-134. doi:10.1111/j.1465-7295.2008.00164.x.

Andreoli-Versbach, P., Franck, J.U., 2015. Endogenous price commitment, sticky and leadership pricing: Evidence from the Italian petrol market. International Journal of Industrial Organization 40, 32-48. doi:10.1016/j.ijindorg.2015.02.006.

Angerer, M., 2019. Regulation of retail gasoline prices. Finance Research Letters doi:10.1016/j.frl.2019.101331. In press.

Bauhoff, S., 2014. The effect of school district nutrition policies on dietary intake and overweight: a synthetic control approach. Economics \& Human Biology 12, 45-55. doi:10.1016/j.ehb.2013.06.001.

Bello, A., Contín-Pilart, I., 2012. Taxes, cost and demand shifters as determinants in the regional gasoline price formation process: Evidence from spain. Energy Policy 48, 439-448. doi:10.1016/j.enpol.2012.05.069.

Berninghaus, S., Hesch, M., Hildenbrand, A., 2012. Zur Wirkung regulatorischer Preiseingriffe auf dem Tankstellenmarkt. Wirtschaftsdienst 92, 46-50. doi:10.1007/s10273012-1322-2. 
BMWFJ, 2009. 190. Verordnung: Standesregeln für Tankstellenbetreiber über den Zeitpunkt der Preisauszeichnung für Treibstoffe bei Tankstellen. https ://rdb .manz . at/ document/ris.c.BGBI__II_Nr__190_2009, [Online; accessed 09-November-2020].

BMWFJ, 2010. 484. Verordnung: Standesregeln für Tankstellenbetreiber über den Zeitpunkt der Preisauszeichnung für Treibstoffe bei Tankstellen. https://www.ris . bka.gv .at/eli/bgbl/II/2010/484, [Online; accessed 09-November-2020].

BMWFJ, 2011. Preistransparenzverordnung Treibstoffpreise 2011. https: //www . ris.bka.gv . at/GeltendeFassung . wxe?Abfrage=Bundesnormen\& Gesetzesnummer=20007391\&FassungVom=2019-12-31, [Online; accessed 31August-2020].

BMWFJ, 2012. 186. Verordnung: Änderung der Verordnung betreffend Standesregeln für Tankstellenbetreiber über den Zeitpunkt der Preisauszeichnung für Treibstoffe bei Tankstellen. https://www.ris.bka.gv.at/Dokumente/BgblAuth/BGBLA_2012_ II_186/BGBLA_2012_II_186.pdfsig, [Online; accessed 09-November-2020].

BMWFJ, 2013. 471. Verordnung: Änderung der Verordnung betreffend Standesregeln für Tankstellenbetreiber über den Zeitpunkt der Preisauszeichnung für Treibstoffe bei Tankstellen und der Preistransparenzverordnung Treibstoffpreise 2011. https: // www.ris.bka.gv.at/eli/bgbl/II/2013/471, [Online; accessed 30-November-2020].

Bohn, S., Lofstrom, M., Raphael, S., 2014. Did the 2007 Legal Arizona Workers Act reduce the state's unauthorized immigrant population? Review of Economics and Statistics 96, 258-269. doi:10.1162/REST_a_00429.

Borenstein, S., Shepard, A., 1996. Dynamic Pricing in Retail Gasoline Markets. Rand Journal of Economics 27, 429-451. doi:10.2307/2555838.

Byrne, D.P., De Roos, N., 2019. Learning to coordinate: A study in retail gasoline. American Economic Review 109, 591-619. doi:10.1257/aer.20170116.

Byrne, D.P., de Roos, N., 2020. Startup Search Costs. American Economic Journal: Microeconomics , 1-45.

Carranza, J.E., Clark, R., Houde, J.F., 2015. Price controls and market structure: Evidence from gasoline retail markets. The Journal of Industrial Economics 63, 152198. doi:10.1111/joie.12071. 
Contín-Pilart, I., Correljé, A.F., Palacios, M.B., 2009. Competition, regulation, and pricing behaviour in the spanish retail gasoline market. Energy Policy 37, 219-228. doi:10.1016/j.enpol.2008.08.018.

Dewenter, R., Heimeshoff, U., Lüth, H., et al., 2017. Less pain at the pump? The effects of regulatory interventions in retail gasoline markets. Applied Economics Quarterly 63, 259-274. doi:10.3790/aeq.63.3.259.

Doudchenko, N., Imbens, G.W., 2016. Balancing, regression, difference-in-differences and synthetic control methods: A synthesis. Technical Report. National Bureau of Economic Research.

Eckert, A., 2013. Empirical studies of gasoline retailing: A guide to the literature. Journal of Economic Surveys 27, 140-166. doi:10.1111/j.1467-6419.2011.00698.x.

Eckert, A., West, D.S., 2004. A tale of two cities: Price uniformity and price volatility in gasoline retailing. Annals of Regional Science 38, 25-46. doi:10.1007/s00168-0030144-y.

Fachverband Mineralölindustrie, 2019. Branchenreport Mineralöl 2018. https://www . wko .at/branchen/industrie/mineraloelindustrie/ branchenreport-mineraloelindustrie-2018.pdf, [Online; accessed 17-March2020].

Fasoula, E., Schweikert, K., 2020. Price regulations and price adjustment dynamics: Evidence from the Austrian retail fuel market. Journal of Transport Economics and Policy 54, 21-39.

Gardeazabal, J., Vega-Bayo, A., 2017. An empirical comparison between the synthetic control method and Hsiao et al.'s panel data approach to program evaluation. Journal of Applied Econometrics 32, 983-1002. doi:10.1002/jae.2557.

Genakos, C., Koutroumpis, P., Pagliero, M., 2018. The Impact of Maximum Markup Regulation on Prices. Journal of Industrial Economics 66, 239-300. doi:10.1111/joie.12175.

Haucap, J., Müller, H.C., 2012. The Effects of Gasoline Price Regulations: Experimental Evidence. DICE Discussion Papers 47. doi:10.2139/ssrn.2482288. 
Hsiao, C., Steve Ching, H., Ki Wan, S., 2012. A panel data approach for program evaluation: Measuring the benefits of political and economic integration of Hong Kong with mainland China. Journal of Applied Econometrics 27, 705-740. doi:10.1002/jae.1230.

IEA, 2009. Energy policies of IEA countries: Luxembourg 2008 Review. https://www.iea.org/reports/ energy-policies-of-iea-countries-luxembourg-2008-review, [Online; accessed 15-March-2020].

IEA, 2011. Energy policies of IEA countries: Belgium 2009 Review. https://www . iea. org/reports/energy-policies-of-iea-countries-belgium-2009-review, [Online; accessed 15-March-2020].

IEA, 2014. Energy policies of IEA countries: Austria 2014 Review. https: //www . iea . org/reports/energy-policies-of-iea-countries-austria-2014-review, [Online; accessed 15-March-2020].

Jardón, A., Kuik, O., Tol, R.S., 2020. Causal Effects of PetroCaribe on Sustainable Development: A Synthetic Control Analysis. Manchester School 88, 156-210. doi:10.1111/manc. 12275 .

Johnson, R.N., 2002. Search Costs , Lags and Prices at the Pump. Review of Industrial Organization 20, 33-50. doi:10.1023/A:1013364513064.

Karathodorou, N., Graham, D.J., Noland, R.B., 2010. Estimating the effect of urban density on fuel demand. Energy Economics 32, 86-92. doi:10.1016/j.eneco.2009.05.005.

Kaul, A., Klößner, S., Pfeifer, G., Schieler, M., 2015. Synthetic control methods: Never use all pre-intervention outcomes together with covariates. Working paper.

Klößner, S., Kaul, A., Pfeifer, G., Schieler, M., 2018. Comparative politics and the synthetic control method revisited: A note on Abadie et al.(2015). Swiss Journal of Economics and Statistics 154, 1-11. doi:10.1186/s41937-017-0004-9.

Kreif, N., Grieve, R., Hangartner, D., Turner, A.J., Nikolova, S., Sutton, M., 2016. Examination of the synthetic control method for evaluating health policies with multiple treated units. Health economics 25, 1514-1528. doi:10.1002/hec.3258. 
Lewis, M.S., 2011. Asymmetric price adjustment and consumer search: An examination of the retail gasoline market. Journal of Economics \& Management Strategy 20, 409449. doi:10.1111/j.1530-9134.2011.00293.x.

Li, K.T., 2019. Statistical inference for average treatment effects estimated by synthetic control methods. Journal of the American Statistical Association , 116doi:10.1080/01621459.2019.1686986.

Montag, F., Winter, C., 2020. Transparency Against Market Power. SSRN Electronic Journal , 1-77doi:10.2139/ssrn.3256476.

Newman, P.W., Kenworthy, J.R., 1989. Gasoline consumption and cities: a comparison of US cities with a global survey. Journal of the American planning association 55, 24-37. doi:10.1080/01944368908975398.

Obradovits, M., 2014. Austrian-style gasoline price regulation: How it may backfire. International Journal of Industrial Organization 32, 33-45. doi:10.1016/j.ijindorg.2013.10.009.

OECD, 2013. Competition in road fuel. https://www.oecd.org/competition/ CompetitionInRoadFuel.pdf, [Online; accessed 04-February-2020].

Pennerstorfer, D., Schmidt-Dengler, P., Schutz, N., Weiss, C., Yontcheva, B., 2020. Information and price dispersion: Theory and evidence. International Economic Review 61, 871-899. doi:10.1111/iere.12443.

Perdiguero, J., 2010. Dynamic pricing in the spanish gasoline market: A tacit collusion equilibrium. Energy Policy 38, 1931-1937. doi:10.1016/j.enpol.2009.11.073.

Perdiguero-García, J., 2013. Symmetric or asymmetric oil prices? A meta-analysis approach. Energy policy 57, 389-397. doi:10.1016/j.enpol.2013.02.008.

Peri, G., Yasenov, V., 2019. The labor market effects of a refugee wave synthetic control method meets the mariel boatlift. Journal of Human Resources 54, 267-309.

Pinotti, P., 2015. The economic costs of organised crime: Evidence from Southern Italy. The Economic Journal 125, F203-F232. doi:10.1111/ecoj.12235. 
Rickman, D., Wang, H., 2020. What goes up must come down? The recent economic cycles of the four most oil and gas dominated states in the US. Energy Economics 86, 1-16. doi:10.1016/j.eneco.2020.104665.

Rickman, D.S., Wang, H., Winters, J.V., 2017. Is shale development drilling holes in the human capital pipeline? Energy Economics 62, 283-290. doi:10.1016/j.eneco.2016.12.013.

Sen, A., Clemente, A., Jonker, L., 2011. Retail gasoline price ceilings and regulatory capture: Evidence from Canada. American Law and Economics Review 13, 532-564. doi:10.1093/aler/ahr008.

Stigler, G.J., 1961. The economics of information. Journal of Political Economy 69, 213-225. doi:10.1086/258464.

Suvankulov, F., Lau, M.C.K., Ogucu, F., 2012. Price regulation and relative price convergence: Evidence from the retail gasoline market in Canada. Energy Policy 40, 325-334. doi:10.1016/j.enpol.2011.10.015.

Wadud, Z., 2016. Diesel demand in the road freight sector in the UK: Estimates for different vehicle types. Applied Energy 165, 849-857. doi:10.1016/j.apenergy.2015.12.102.

Wang, Z., 2009. (Mixed) strategy in oligopoly pricing: Evidence from gasoline price cycles before and under a timing regulation. Journal of Political Economy 117, 9871030. doi:10.1086/649801.

Yang, H., Ye, L., 2008. Search with learning: Understanding asymmetric price adjustments. RAND Journal of Economics 39, 547-564. doi:10.1111/j.07416261.2008.00027.x. 